\title{
Pyrolytic Carbon Nanograss Enhances Neurogenesis and Dopaminergic Differentiation of Human Midbrain Neural Stem Cells
}

Asif, Afia; García-López, Silvia; Heiskanen, Arto; Martínez-Serrano, Alberto; Keller, Stephan Sylvest; Pereira, Marta P.; Emnéus, Jenny

Published in:

Advanced Healthcare Materials

Link to article, DOI:

10.1002/adhm.202001108

Publication date:

2020

Document Version

Peer reviewed version

Link back to DTU Orbit

Citation $(A P A)$ :

Asif, A., García-López, S., Heiskanen, A., Martínez-Serrano, A., Keller, S. S., Pereira, M. P., \& Emnéus, J. (2020). Pyrolytic Carbon Nanograss Enhances Neurogenesis and Dopaminergic Differentiation of Human Midbrain Neural Stem Cells. Advanced Healthcare Materials, 9(20), [2001108].

https://doi.org/10.1002/adhm.202001108

\section{General rights}

Copyright and moral rights for the publications made accessible in the public portal are retained by the authors and/or other copyright owners and it is a condition of accessing publications that users recognise and abide by the legal requirements associated with these rights.

- Users may download and print one copy of any publication from the public portal for the purpose of private study or research.

- You may not further distribute the material or use it for any profit-making activity or commercial gain

- You may freely distribute the URL identifying the publication in the public portal 


\section{WILEY-VCH}

Pyrolytic Carbon Nanograss Enhances Neurogenesis and Dopaminergic Differentiation of Human Midbrain Neural Stem Cells

Afia Asif, Dr. Silvia Gracía-López, Dr. Arto Heiskanen, Prof. Alberto Martínez-Serrano, Dr. Stephan S. Keller, Dr. Marta Pereira, and Prof. Jenny Emnéus*

A. Asif, Dr. A. Heiskanen, Prof. J. Emnéus

Department of Biotechnology and Biomedicine (DTU Bioengineering)

Produktionstorvet, Building 423, Room 122, 2800 Kgs. Lyngby, Denmark

E-mail: jemn@dtu.dk

Dr. S.S. Keller

National Centre for Nano Fabrication and Characterization (DTU Nanolab)

Ørsteds Plads, Building 347, 2800 Kgs. Lyngby, Denmark

Dr. S. Gracía-López, Dr. M. Pereira, Prof. A. Martínez-Serrano

Department of Molecular Biology, Universidad Autónoma Madrid; Dept. of Molecular

Neuropathology, Center of Molecular Biology Severo Ochoa (UAM-CSIC).

Nicolás Cabrera 1, 28049-Madrid. Spain

Keywords: Pyrolytic, Carbon nanograss, Dopaminergic Differentiation, Human Neural Stem Cells, Parkinson's Disease 


\section{WILEY-VCH}

\section{Abstract}

Advancements in research on the interaction of human neural stem cells (hNSCs) with nanotopographies and biomaterials are enhancing the ability to influence cell migration, proliferation, gene expression, and tailored differentiation towards desired phenotypes. Here, we report the fabrication of pyrolytic carbon nanograss (CNG) nanotopographies and demonstrate that these can be employed as cell substrates boosting hNSCs differentiation into dopaminergic neurons (DAn), a long-time pursued goal in regenerative medicine based on cell replacement. In the near future, such structures could play a crucial role in the near future for stem-cell based cell replacement therapy (CRT) and bio-implants for Parkinson's disease. The unique combination of randomly distributed nanograss topographies and biocompatible pyrolytic carbon material is optimized to provide suitable mechano-material cues for hNSCs adhesion, division, and DAn differentiation of midbrain hNSCs. The results show that in the presence of the biocoating poly-L-lysine (PLL), the CNG enhances hNSCs neurogenesis up to 2.3 folds and DAn differentiation up to 3.5 folds. Moreover, for the first time, consistent evidence is provided, that CNGs without any PLL coating, are not only supporting cell survival but also lead to significantly enhanced neurogenesis and promote hNSCs to acquire dopaminergic phenotype compared to PLL coated topographies.

\section{Introduction}

Stem cells are undifferentiated cells with the properties of self-renewal and to develop into multiple specialized cells on demand, induced by certain environmental physical and biological cues and signals. To understand how to harness the stem cells potential for replacing damaged cells in the mammalian nervous system, and the mechanisms regulating their differentiation, data from in vitro tested culture conditions suggest that stem cells respond to environmental 


\section{WILEY-VCH}

cues including substrate composition, chemical surroundings, and physico-structural properties of the substrate. The latter include rigidity, topological features, and surface biochemistry. ${ }^{[1]}$ Dopamine (DA), an organic chemical of the catecholamine and phenethylamine families, is a neurotransmitter in the nervous system, transmitting information between neurons through synapses and assisting to regulate several vital functions in the brain such as voluntary movements, emotions, rewards and learning responses, among others. Due to its high involvement in motor systems function, a wide range of research has elaborated its importance for clinical therapy of Parkinson's disease (PD), a neurodegenerative disease in which the loss of DA-secreting neurons in Substantia Nigra pars compacta (SNpc), leads to appearance of motor symptoms, including tremor, rigidity, hypokinesia and globally impaired motor function. ${ }^{[2]}$ Cell replacement therapy (CRT) using stem cells is one of the proposed future strategies for PD treatment, meant to restore DA deficiencies by transplanting cells that possess dopaminergic phenotype in the SNpc target areas (caudate and putamen of the striatum in the brain) of patients. ${ }^{[2,3]}$ The interest to use stem cells in CRT for PD has led to several clinical trials during the past few years. ${ }^{[4-7]}$ However, fundamental research is needed to investigate the potential of stem cells to differentiate into DAn when using neural stem cells as an implant for PD.

As of today, cell cultures are routinely established on commercial, two-dimensional (2D) flat tissue culture polystyrene (TCP) for proliferation and differentiation experiments. ${ }^{[8,9]}$ However, recent studies with cells such as osteoblasts and fibroblasts suggest that low aspect ratio topographical surfaces are viable alternatives to commercial $2 \mathrm{D}$ cell substrates. ${ }^{[10-12]}$ In particular, the emergence of micro and nanofabrication techniques has given rise to new types of $3 \mathrm{D}$ cell-culture platforms to study the effects of various topographical cues on cellular morphology, migration, adhesion, gene expression, proliferation, and differentiation. ${ }^{[13-16]}$ Photolithography, nanoimprint lithography, and 3D micro-printing technologies are commonly used methods for creating micro and nano-topographies due to their low cost, precision for 


\section{WILEY-VCH}

periodic geometries, high reproducibility and control over structural dimensions on a scale from nanometer $(\mathrm{nm})$ to micrometer $(\mu \mathrm{m}) \cdot{ }^{[17]}$ Biocompatible materials, ${ }^{[18,19]}$ in a combination with physical parameters of 3D structures, such as shape, ${ }^{[20]}$ feature height, ${ }^{[21,22]}$ aspect ratio, effective stiffness, ${ }^{[23]}$ and structural density, ${ }^{[21-24]}$ play a vital role to build artificial tissues, organs, and implants, ${ }^{[19]}$ for stem cell-based regenerative therapies.

Besides periodic and well-defined structures, research studies on more random micro- and nanotopographies emphasize the importance of substrate roughness in accordance with neural cell attachment and viability. Due to its better in vivo resemblance, surface roughness, ranging from 0-64 $\mathrm{nm}$ is considered to have significant influence on neural cell attachment by affecting the contact area of the cell-membrane with the surface ${ }^{[25,26]}$ Furthermore, it has been observed that cells from substantia nigra can adhere and survive better on surfaces with roughness ranging from $20-50 \mathrm{~nm} \cdot{ }^{[27]}$

Recent advancements and increased knowledge point towards carbon nanomaterials as being safe for biomedical applications. However, the biocompatibility of carbon nanomaterials is yet an open debate ${ }^{[28,29]}$ Conductive cell scaffolds are of great interest to study inherent neuronal electroactivities since these structures provide both structural support and electrical means for stimulating cell population or read-out of the response by electrochemical techniques. ${ }^{[30-39]}$ Carbon nanomaterials such as graphene and carbon nanotubes (CNT) have been studied as substrates for facilitating growth, differentiation and electrical stimulation of neural stem cells, due to their biocompatibility and conductive nature of the material. ${ }^{[32]}$ The fabrication of pyrolytic carbon scaffolds is achieved through pyrolysis, a process that encompasses the gradual heating and carbonization of polymer precursors at high temperatures in a controlled and inert environment. The pyrolysis process was pioneered in the $1970 \mathrm{~s},{ }^{[40]}$ and the fabrication of carbon-based micro ${ }^{[41-43]}$ and nanostructures ${ }^{[42-44]}$ has become increasingly popular due to the process simplicity, cost-effectiveness, and large-scale reproducibility. Pyrolytic carbon 


\section{WILEY-VCH}

materials have among others been used for applications in biosensors, ${ }^{[45]}$ micro-batteries, ${ }^{[42]}$ and as cell culture substrates. ${ }^{[46]}$

In this work, we fabricated and characterized pyrolytic $\mathrm{CNG}$ structures and investigated the role of nanotopography and materials on the biology of hNSCs. Four different types of CNG were fabricated by a simple process consisting of photolithography, reactive ion etching and pyrolysis for carbonization. To determine the effects of CNG surfaces on the hNSCs biology, we have used a thoroughly characterized v-myc immortalized human fetal NSCs of ventral mesencephalic origin, characterized for its great potential generating SNpc subgroup A9 bonafide DA neurons. ${ }^{[8,47-52]}$ Analysis of hNSCs differentiation was achieved by quantifying morphological parameters such as cell area, elongation, and circularity. Moreover, specific biomarkers were analyzed to investigate neurogenesis and DAn generation on CNGs as compared to on TCP control and flat carbon (FC) surfaces. Cell studies were conducted both in the presence and absence of a biocoating, in this case PLL, to evaluate the effect on cell adhesion and differentiation. The overall aim of the experimental study was to identify if pyrolytic $\mathrm{CNG}$ is a promising engineered nanomaterial to use as a future platform in CRT and implants for PD treatment.

\section{Results and Discussions}

\subsection{Fabrication of Carbon Nanograss}

The overall aim was to fabricate cell substrates with $\mathrm{CNG}$ structures presenting i) variable interspaces as focal points for cell adhesion both on top of and in between the CNG, and ii) different nanograss heights in order to investigate their effects on cells in terms of adhesion, morphology, proliferation, and differentiation. The complete three-step process to fabricate CNGs is illustrated in Figure 1A-C. First, a $15 \mu \mathrm{m}$ thick film of negative epoxy-based 


\section{WILEY-VCH}

photoresist SU-8 was prepared by one step of conventional photolithography without photomask (Figure 1A). We then obtained the polymer nanograss by etching the SU-8 layer using maskless reactive ion etching (RIE) in oxygen plasma (Figure 1B). It has been reported earlier that during this RIE process, the antimony originating from the SU-8 photo-initiator accumulates on the surface of the etched SU-8. There, it is acting as a local micromasking component during further etching which results in hairlike SU-8 structures. ${ }^{[43,53]}$ Finally, the SU-8 nanograss precursor structures were converted into $\mathrm{CNG}$ by pyrolysis at $900^{\circ} \mathrm{C}$ in an inert atmosphere (Figure 1C).

A preliminary experimental study of RIE oxygen plasma (results not shown here) identified the etching time as the main parameter affecting the SU-8 surface in terms of penetration depth. The height of the nanograss increased with an increased etching time. Four different CNG heights were fabricated by varying the etching time in the oxygen plasma from 5 to 20 mins (CNG5, CNG10, CNG15, and CNG20) and the resulting nanostructures are shown as tiltedview in Figure 1D-G.

After maskless RIE with oxygen plasma, the SU-8 surface displayed nanograss clusters that were groups of several hairlike structures. Figure 1 shows that the clusters were maintained after pyrolysis. It can be observed that increased etch times led to larger interspaces between the resulting $\mathrm{CNG}$ clusters shown in top-view in Figure $1 \mathrm{H}-\mathrm{K}$. The longer etch times provided deeper etching of SU-8 and resulted in higher CNG clusters with heights ranging from $1.5 \mu \mathrm{m}$ to $7.5 \mu \mathrm{m}$ for CNG5 to CNG20, respectively (cross-sectional view; Figure 1L-O). These results also show that the remaining bottom layer of carbon below the grass was gradually reduced from CNG5 to CNG20 for longer etch times. The detailed dimensions of nanograss clusters in terms of height, interspace and bottom layer thickness are listed in Table1. It is important to note that shrinkage during the pyrolysis process resulted in structural heights below the thickness of the initial SU-8 film. 


\section{WILEY-VCH}

After the completed fabrication, the CNG substrates were highly hydrophobic due to the nanograss structures formed on the surface. This hydrophobic behavior of the substrate is a challenge for cell experimentation as it tends to obstruct surface wettability. Therefore, to ensure surface hydrophilicity for cell experiments, the CNG samples were treated with oxygen plasma prior to PLL coating. The water contact angle (WCA) was measured before and after plasma exposure and the recorded values are summarized in Table1 (images in Table S1 (Supporting information)). The WCA values for samples after oxygen plasma treatment were below the limit of detection of the equipment used, showing superhydrophilicity for the CNG surfaces. The obtained data in Table 1 confirmed that substrates turned from hydrophobic to superhydrophilic after plasma treatment, which is expected to facilitate the interaction of media and cells with the CNG substrates.

\subsection{Adhesion and Viability of hNSCs}

Typically, substrates for cell and tissue cultures in biological and biomaterial interaction studies are coated with proteins to promote cell adhesion. In order to adhere, proliferate and differentiate on regular (flat) tissue culture polystyrene (TCP), hNSCs require adhesion factors such as PLL. However, to examine the ultimate role of structural nano/micro environment on basic cell biology, and to ascribe hypothesized differences in cell fate choices to topographical and material aspects, all surfaces in this study were examined both with and without PLL. Oxygen plasma treatment was performed on glass and pyrolytic carbon samples before starting cellular studies, but not on TCP as commercial TCP is already treated with plasma and surface modifications. hNSCs were seeded at a density of 50,000 cells $/ \mathrm{cm}^{2}$ and the adhesion and viability of cells were assessed after 3 days of proliferation and 10 days of differentiation.

Cell adhesion and growth was investigated for a flat pyrolytic carbon (FC) substrate and the four types of CNGs with (Figure 2C, E-H) and without PLL coating (Figure 2D, I-L) and the 


\section{WILEY-VCH}

results were compared with PLL coated TCP and glass controls (Figure 2A-B) using scanning electron microscopy (SEM).

Cells under proliferating conditions were fixed on day 3 and the nuclei were labelled with DAPI dye and quantified. Nuclei quantification revealed that on the lower nanograsses e.g. CNG5, cells reached significantly higher density than cells seeded on the higher nanograsses e.g. CNG20 (Figure 2M). In comparison to the TCP and FC control, the cell numbers were significantly lower on all CNG surfaces. Furthermore, the cell density on FC was significantly lower than on TCP, which is probably because commercial tissue culture substrates are pretreated with a variety of negatively charged functional groups supporting cell attachment, spreading and growth. The cell numbers obtained on PLL coated glass surfaces were almost equivalent to PLL coated FC (Figure 2M), consistent with the fact that the glass and the carbon surfaces were all treated with oxygen plasma only. For the uncoated TCP and glass controls, no cell adhesion was observed (results not included in SEM data). In the case of the uncoated FC, hNSCs could only adhere in form of cell clumps for 2-3-days (Figure 2D), whereas cells adhered well and increased in density during proliferation on PLL coated FC (Figure 2C). The clustered cells on uncoated FC had spherical cell morphology, which confirmed that PLL coating is necessary for cell adhesion on all flat surfaces. Overall, the results indicate that the CNG substrates support hNSCs adhesion and growth both with PLL coating (Figure 2E-H), and surprisingly also without PLL coating (Figure 2I-L).

It is remarkable that the cell numbers acquired on all four types of $\mathrm{CNG}$ were very similar with and without PLL coating. This demonstrates that cell adhesion and growth is independent of the biocoating on the CNG structures, probably due to structural support and focal adhesion points that are provided by the $\mathrm{CNG}$ topographies, which are absent on flat surfaces.

Similarly, the hNSCs cell number on both PLL coated and uncoated substrates was examined after 10 days of differentiation (Figure 2N). As explained above for the uncoated TCP, glass and FC, the cell count was zero because cell adhesion could not be sustained on the flat surfaces 


\section{WILEY-VCH}

long enough to allow differentiation. The DAPI count after 10 days of differentiation showed no difference in the cell number on the different CNG surfaces between PLL coated and uncoated surfaces.

\subsection{Morphological Analysis of Differentiated hNSCs}

The effect of topography the influence of PLL coated and uncoated substrates on morphology and adhesion of hNSCs during differentiation was examined using SEM analysis of cells on the CNG samples in comparison to cells seeded on TCP, glass, and FC, both in with and without PLL coating. hNSCs were cultured for 24 hours at a density of 50,000 cells $/ \mathrm{cm}^{2}$ and the morphology of cells was assessed after 10 days of differentiation in differentiation medium (details in section 4). In order to provide quantitative data supporting morphological observations, physical dimensions of cells, in terms of shape were measured by calculating cell area, elongation, and circularity.

For PLL coated surfaces, Figure 3 shows that the neural cell body of differentiated hNSCs presented increasingly spherical morphology as the CNG height increases from CNG5 to CNG20 (Figure 3E-H). The same observation was valid when comparing these CNG substrates with the PLL coated FC, TCP, and glass surfaces (Figure 3A-C). The morphological parameters, i.e., hNSC area, elongation, and circularity for all surfaces are shown in Figure 3M-O. The obtained data shows that the cell area (Figure $3 \mathrm{M}$ ) is highest on flat PLL coated surfaces and then decreases with increasing CNG height (from CNG5 to CNG20). Thus, cells tend to spread more on the flat PLL coated surfaces as compared to the PLL coated CNGs, which confirms results reported for progenitor mouse neural stem cells. ${ }^{[54]}$ Similarly, the cell elongation on PLL coated surfaces, characterized as the cell aspect ratio (Figure $3 \mathrm{~N}$ ), was highest for flat surfaces and then decreasing substantially with increasing CNG height. On the other hand, the cellcircularity, which is the ratio of the area to the perimeter, increases for PLL coated surfaces 


\section{WILEY-VCH}

from TCP to FC and from FC to CNG20, confirming the spherical morphology of hNSCs (Figure 30).

For uncoated surfaces, the FC control (Figure 3D) shows no cell adherence since cells started detaching on day 2 of differentiation similar as for uncoated TCP and glass substrates (results not shown). The results demonstrate on the other hand that uncoated CNGs promote strong cell adhesion, which leads to a relatively flat cell morphology (Figure 3I-L) compared to PLL coated CNG (Figure 3E-H). Figure 3M indicates that the hNSCs cytoskeleton structure spread along several focal-planes on the uncoated CNGs, resulting in almost doubling of the cell-area as compared to PLL coated CNG. Figure $3 \mathrm{~N}$ shows that uncoated CNGs display less cell elongation as compared to cells on PLL coated CNG. Finally, the cell circularity increases from CNG5 to CNG20 similar as for PLL coated topographies (Figure 3O).

\subsection{Material Influence on Neurogenesis and DAn generation}

To study the effect of pyrolytic carbon material on hNSCs differentiation, the cells were differentiated for 10 days on FC surfaces, and their phenotype was assessed by immunocytochemistry for TUBB3 (neuronal) and TH (DAn) markers. After 10 days of differentiation, the cell cultures exhibited highly differentiated phenotype with a high yield of DAn (Figure 4). The hNSCs differentiated very well on PLL coated FC, displaying normal neuronal morphology, and an increase of neurogenesis by $33 \%$ and DAn generation by $63 \%$ when compared to the PLL coated TCP control and glass control (Figure 4A-C). These results are consistent with previous results, ${ }^{[34]}$ where it was observed that the pyrolytic carbon material plays an important role in DAn differentiation and seems to be better suited as cell-substrate than TCP.

The experiment was further expanded to compare the carbon material with its flat precursor polymer SU-8 and to evaluate the effects of the SU-8 material on differentiation. The results 


\section{WILEY-VCH}

showed that on PLL coated flat SU-8 surfaces, cells adhered but less cells were able to differentiate into DAn (Figure S1C (Supporting information)). SU-8, an epoxy photoresist, has been demonstrated as a suitable material for biomedical applications, including usage as neural

implants. ${ }^{[55,56]}$ Its potential cytotoxicity is attributed to the epoxy monomers and antimony salt used as the photoinitiator. ${ }^{[55]}$ However, treatment such as UV flood exposure combined with hard bake, $\mathrm{O}_{2}$ plasma, and protein coating has been demonstrated to enhance its biocompatibility. ${ }^{[56-58]}$ Our results show that despite the above pre-treatments and a PLL coating on the SU-8, the hNSCs could only adhere and proliferate but not differentiate very well into DAn. Hence, the ultimate classification of SU-8 as a biocompatible material is highly dependent on the used cellular model and the monitored biological function. In the case of uncoated FC (Figure 4D), cells formed clumps instead of monolayers and detached on day 2 of differentiation. On uncoated TCP control, glass and SU-8 surfaces no cells were observed (Figure S1E-G (Supporting information)), which confirms that all flat substrates need a biocoating such as PLL, for hNSCs adhesion, growth, and differentiation.

\subsection{Topological Influence on Neurogenesis and DAn generation}

The influence of CNG topographies on neurogenesis and DAn differentiation was investigated by differentiating hNSCs on PLL coated and uncoated CNG5-20. The CNG topographies were compared with regular TCP and FC controls using SEM and ICC fluorescent imaging for TH, TUBB3, and DAPI. Fluorescence images and corresponding quantitative data in Figure 4 show the effect of CNGs on hNSCs maturation and fate. ICC images of PLL coated TCP control, glass, FC (Figure 4A-C), uncoated FC (Figure 4D), PLL coated CNG5-20 (Figure 4E-H) and uncoated CNG structures (Figure 4I-L), indicate that CNGs enhance both the differentiation/maturation of hNSCs into neurons, and more specifically into DAn, both with and without the presence of PLL. This is supported by quantification of the total number of 


\section{WILEY-VCH}

cells (DAPI stained nuclei), neurons (TUBB3), and DAn (stained for TH). Figure 4M-O shows the detailed quantitative results for PLL coated materials and topographies in terms of the percentage of neurons from the total cells represented as TUBB3 / DAPI, the percentage of DAn in the total cell population represented as $\mathrm{TH}^{+}$Neurons / DAPI, and the percentage of DAn relative to the total number of neurons represented as $\mathrm{TH}^{+}$neurons / $\mathrm{TUBB} 3$ (indicative of specific effects on DAn generation). A statistical significance analysis $(\alpha<0.05)$ using oneway ANOVA followed by Dunnett's post-hoc test was performed to assess differences in the presence of TUBB3 and TH biomarkers for all types of topographies.

In the case of neurogenesis on PLL coated surfaces (Figure 4M), it is clear that more cells mature into neurons on carbon compared to TCP and glass, and increasingly more for $\mathrm{CNG}$ substrates with higher nanostructures. The statistical analysis of the data in Figure 4M shows highly significant differences $(* * * * \mathrm{P}<0.0001)$ for $\mathrm{FC}$ and $\mathrm{CNG}$ compared to TCP, and $\mathrm{CNG}$ compared to FC. The analysis revealed that due to the CNG, neurogenesis increased 2.3 folds for the CNG15 compared to the TCP control (Table S2 (Supporting information)). Furthermore, a 1.7 folds increase in neurogenesis was observed on CNGs compared to the FC control (Table S3 (Supporting information)). Similarly, statistical analysis for DAn generation from the entire cell population on PLL coated surfaces (Figure 4N) was performed and a remarkable increase in DAn generation was observed on carbon surfaces compared to TCP, and increasingly more for higher CNG structures. The statistical significance analysis confirmed that due to CNG, dopaminergic neurogenesis in the total cell population increased to $40 \%$, which is an of 3.5 folds improvement in comparison to the TCP material control (Table S2 (Supporting information)) with highly significant differences $(* * * * \mathrm{P}<0.0001)$. Moreover, 2.1 folds increase of dopaminergic neurogenesis was seen on $\mathrm{CNG}$ when compared to the $\mathrm{FC}$ material control (Table S3 (Supporting information)), and this confirms the visual inspection of ICC images in Figure 4E-L discussed above. The total DAn yield of the neuronal population was quantified for PLL coated surfaces (Figure 4O), confirming a remarkable efficiency of CNG 


\section{WILEY-VCH}

substrates for dopaminergic differentiation close to $80 \%$ of the hNSCs differentiated into DAn, which is to our best knowledge has not been achieved before.

Figure 4P-R represents the quantitative analysis of neurogenesis and DAn generation on the uncoated CNGs. Intriguingly, similar trends as for the PLL coated substrates were observed (Figure 4M-O). No cell attachment was observed on uncoated TCP, glass, or FC substrates (Figure S1E, F, H (Supporting information)). Thus, determining the relative increase for uncoated $\mathrm{CNG}$ topographies with respect to uncoated TCP, glass and FC material control was not applicable (Table S4 (Supporting information)). Uncoated and PLL coated CNGs were compared in terms of differences in yield of DAn. The statistical significance analysis $(\alpha<$ 0.05) using two-way ANOVA; Fisher LSD post-hoc test, show 1.5 folds increase in neurogenesis and 1.2 folds increase in DA differentiation for uncoated versus PLL coated CNG with highly significant differences $(* * * * \mathrm{P}<0.0001)$ (Figure S2 and Table S5 (Supporting information)).

For identifying the optimal CNG structure among the four investigated, two-way ANOVA followed by Fisher LSD post-hoc, statistical analysis was performed to compare significant differences for TUBB3 and TH separately with and without coating. It was observed that CNG15 showed highly significant difference $(* * * * \mathrm{P}<0.0001)$ compared to the other CNGs for DAn generation for both coated and uncoated conditions (Tables S6-7 (Supporting information)). However, for neurogenesis, CNG15 and CNG20 structures were equally good in comparison to CNG5 and CNG10 with highly significant differences of $(* * * * \mathrm{P}<0.0001)$ and $(* * * \mathrm{P}<0.001)$, respectively (Tables S8-9 (Supporting information)). These results indicate that further increase of the etching time, beyond the investigated range probably will not result in additional benefit for DAn generation.

Gene expression analysis by qPCR, RT-PCR and western blot (WB) was performed to verify the dopaminergic nature of the differentiated cells (Figure S3 and S4 (Supporting Information)). To determine if the $\mathrm{TH}^{+}$population corresponds to the presence of dopaminergic neurons, we 


\section{WILEY-VCH}

carried out qPCR and end-point RT-PCR of GIRK2, which is particularly expressed in dopaminergic neurons of the SN and VTA, and dopamine beta-hydroxylase (DBH), which is specifically expressed in noradrenaline and adrenaline secreting neurons (Figure S3B and C for PLL coated surfaces (in the Supporting Information)). We did not find any statistically significant differences in GIRK2 between most of the hNSCs differentiated on the PLL coated surfaces. Moreover, none of the analyzed conditions showed that hNSCs expressed DBH (Figure S3C (in the Supporting Information)), thereby indicating that the $\mathrm{TH}^{+}$neuronal population of the differentiated cell cultures corresponds to a dopaminergic neuronal phenotype. In order to understand the reason for the increased neurogenesis on the CNGs, we performed qPCR and western blot analysis of doublecortin (DCX) (i.e., an immature neuron marker) to make a clear comparison of the CNGs (Figure S3A and S4B). The qPCR analysis of DCX did not show any statistically significant differences for the PLL coated CNGs compared to PLL coated TCP control (Figure S3A). However, when protein analysis was conducted using western blot, the DCX protein content was significantly decreased for PLL coated CNGs compared to PLL coated TCP control (Figure S4B). The DCX western blot results, together with the ICC analysis performed supports the idea that CNG surfaces enhance a more mature DAn culture than TCP or FC surfaces. Surprisingly, no statistically significant decrease in DCX protein content was detected for uncoated CNG substrates in comparison to the PLL coated TCP control. Taking the inability of the uncoated TCP or FC surfaces to sustain hNSCs into account, we can conclude that uncoated CNGs entail a clear enhancement of hNSCs differentiation, even though they might need an extra differentiation time to mature as compared to PLL coated CNGs. Consistent with a more immature culture of differentiated hNSCs on uncoated CNGs, these cells also display a less elongated morphology (Figure 3N), as compared to PLL coated CNGs, which correlates with shorter neurites observed in immature neurons. ${ }^{[59,60]}$ hNSCs were also differentiated on SU-8 nanograss structures (i.e., polymer nanograss precursor of the CNGs), serving as a nanograss structural control. The PLL coated SU-8 nanograss 


\section{WILEY-VCH}

facilitated cell adhesion, but it is clear from the ICC results that very few cells could differentiate in DAn (Figure S5A (Supporting information)), as compared to PLL coated CNG, FC and TCP control. Without any coating, SU-8 nanograss did not promote any cell adhesion (Figure S5B (Supporting information)). The lack of cell adhesion despite the presence of nanotopographies may be attributed to cytotoxic material properties such as surface-bound epoxy groups of SU-8.

Interestingly, the above results show that uncoated CNGs perform better than PLL coated structures, achieving significantly enhanced neurogenesis and DAn generation (Figure 4P-Q and Figure S2 (Supporting Information)).

\section{Conclusion}

We have shown that high aspect ratio pyrolytic carbon nanograss $(\mathrm{CNG})$ structures can be fabricated with a simple fabrication process. The pyrolytic CNGs clearly enhances neurogenesis in the overall hNSCs population, leading to a more mature neuronal network. It also demonstrates striking suitability for guiding hNSCs towards increased dopaminergic phenotype. To our knowledge, this is the first time an in-depth study shows quantitative data demonstrating that the appropriate combination of carbon material with nanotopographies leads to enhanced neurogenesis, and particularly DAn differentiation, which could be of help in future PD grafts. Following previous studies on carbon substrates, these results show the potential of pyrolytic CNG structures for enhancing neurogenesis and dopaminergic differentiation, displaying their ability for adhesion, division and differentiation of hNSCs when used with PLL coating, but more importantly when used without any biocoating. This study particularly provides solid data indicating that the biocoating can favorably be eliminated when using CNG substrates for neuronal in vitro and in vivo stem cell studies. Moreover, development of these conductive

pyrolytic CNG nanostructures with their multifunctional nature i.e. conductivity, 


\section{WILEY-VCH}

biocompatibility, and structural support provide new possibilities for programming dopaminergic differentiation and neuronal regeneration for CRT and bio-implants for PD in the future. Moreover, we show that $\mathrm{TH}^{+}$cells in our culture are DAn and that the higher amount of $\mathrm{TH}$ protein on the CNGs suggest a higher production of dopamine neurotransmitter.

As a final remark, biological factors-based protocols have never yielded DAn generation rate from midbrain hNSCs of above $20 \%$ of the total cell population. Our present data on pyrolytic CNG nanotopographies show that it enhances DAn generation to close to $40 \%$ of the total cell population, and close to $80 \%$ of the neuronal population, a remarkable yield, which has not been achieved previously.

\section{Experimental Section}

\section{Carbon nanograss (CNG) fabrication}

We fabricated the CNG substrates based on a conventional UV photolithography process followed by maskless reactive ion etching (RIE) and pyrolysis. Initially, the insulation layer of a $600 \mathrm{~nm} \mathrm{SiO}_{2}$ was deposited on a 4-inch $\mathrm{Si}$ wafer using low-pressure chemical vapor deposition (LPCVD). Approximately $5 \mathrm{ml}$ of negative-tone based epoxy photoresist SU-8 (SU8 2035, MicroChem, USA) was dispensed and spin-coated with an RCD8 T spinner (Süss Micro-Tec, Germany) to deposit a uniform layer of $15 \mu \mathrm{m}$, followed by 30 minutes of soft bake at $50^{\circ} \mathrm{C}$ on a hotplate. Then UV light exposure was performed with an energy dose of $2 \times 250$ $\mathrm{mJ} / \mathrm{cm}^{2}$ with a MA6/BA6 aligner (MA6-001320, Süss Micro-Tec, Germany) using flood exposure followed by 2-hours of post-exposure bake at $50^{\circ} \mathrm{C}$ on a hotplate. Lastly, a hard bake process including UV flood exposure of $2 \times 250 \mathrm{~mJ} / \mathrm{cm}^{2}$ followed by a long bake for 15 -hours at $90^{\circ} \mathrm{C}$ was performed to fully cure any uncured photo initiators left. 


\section{WILEY-VCH}

The crosslinked layer of SU-8 was maskless etched using an Advanced Silicon Etcher (ASE, STS MESC Multiplex. ICP serial no. 30343) having a plasma generating coil of the power of $2000 \mathrm{~W}$, platen-power of $30 \mathrm{~W}$, process pressure of $20 \mathrm{mTorr}$ and using only oxygen gas for four different process etch-time durations $(5,10,15$ and 20 minutes) to achieve four different heights of SU-8 nanograss structures.

The polymeric nanograss precursor structures were pyrolyzed at $900^{\circ} \mathrm{C}$ in an inert nitrogen atmosphere in a PEO604 multipurpose annealing furnace from ATV Technologies GmbH (Vaterstetten, Germany). The pyrolysis protocol included four steps: (i) temperature ramping from room temperature (RT) to $200^{\circ} \mathrm{C}$ for oxygen residual removal, (ii) temperature ramping from $200^{\circ} \mathrm{C}$ to $900^{\circ} \mathrm{C}$ with a rate of $2^{\circ} \mathrm{C} /$ minute, (iii) 1 -hour dwelling time at $900^{\circ} \mathrm{C}$ for carbonization of the polymer and (iv) ramping down temperature to $\mathrm{RT}$ at a rate of $2^{\circ} \mathrm{C} / \mathrm{minute}$.

\section{Dimensional analysis of CNG structures}

Scanning electron microscopy (SEM) on cross-sectional samples obtained by laser dicing from the backside of the wafer was used to examine the height of the nanograss structures. For interspace measurements, top-view SEM images were analyzed to determine the distance between the bright spots that represent the nanograss clusters. The results are presented as average height and interspace with \pm standard deviation for $n=15$, assessed using Fiji image analysis software by NIH.

\section{$\mathrm{O}_{2}$ plasma treatment}

Carbon structures and glass samples were treated with oxygen plasma (TEPLA-600 Plasma Asher, Semi-Auto RF Plasma System) to modify the surfaces from purely hydrophobic to hydrophilic. Initially, the chamber was pumped out entirely to maintain a vacuum. Then oxygen 


\section{WILEY-VCH}

was supplied and plasma was generated at $50 \mathrm{~W}$ of power for 1 minute. Samples were used for cell-culture experiments immediately after plasma treatment.

\section{Water contact angle (WCA) measurements}

The WCA of all samples including FC and all four heights of CNG were analyzed before and after oxygen plasma treatment. OCA-20 with a software package (DataPhysics Instruments $\mathrm{GmbH}$, Germany) was used to measure WCA and results are presented as average with \pm standard deviation for $n=4$.

\section{Preparation of surfaces for cell-based experiments}

After oxygen plasma treatment the carbon and glass surfaces were sterilized by rinsing with $96 \%$ ethanol three times and then completely dried. One set of all carbon and glass substrates was then coated with $20 \mu \mathrm{g} / \mathrm{ml}$ poly-L-lysine (PLL, $1 \mathrm{~g} / \mathrm{mL}$; Sigma, St Louis, MO, USA) in PBS and the TCP control with $10 \mu \mathrm{g} / \mathrm{ml}$ PLL in PBS for 4 hours prior to cell seeding. Another set of all substrates used for cell culture experiments directly without any bio-coating, was treated similarly except for the PLL coating step. All samples (controls, glass and carbon surfaces) were prepared in parallel for all experimental conditions i.e., scanning electron microscopy and immuno-cytochemistry.

\section{Cell culture and differentiation.}

The cell experiments in the present study were conducted with hVM1-Bcl- $\mathrm{X}_{\mathrm{L}}$ cells. These human neural stem cells (hNSCs) are derived from ventral mesencephalic tissue of a 10-weeks old aborted human fetus. The cells were immortalized with v-myc, subsequently modified to enhance Bcl-X $\mathrm{X}_{\mathrm{L}}$ expression levels to preserve their neurogenic capacity. ${ }^{[8,47,48]}$ A hNSCs study on all topographies was conducted at two sets of conditions; 1) Three independent experiments with PLL coated topographies for proliferation (3 days) and differentiation (10 days), and 2) 


\section{WILEY-VCH}

three independent experiments of topographies without PLL coating for proliferation and differentiation. Cells were seeded with the same cell density i.e., 50,000 cells $/ \mathrm{cm}^{2}$ for all substrates in both coated and uncoated conditions. For cell culture, hVM1 cells were first thawed and cultured for 3 passages on TCP. hNSCs were then seeded on all experimental substrates including CNG topographies and flat surfaces, and were supplied with $6 \mathrm{~mL}$ of basic medium containing DMEM/F12 + GlutaMAX (Gibco), and additionally added $6 \mathrm{~g} / \mathrm{L}$ glucose (Sigma Aldrich), 5mM HEPES (Thermofisher Scientific) and $0.5 \% \mathrm{~m} / \mathrm{m}$ AlbuMAX (Thermofisher Scientific). This basic medium was then supplemented with 100x diluted N-2 supplement (Gibco), Non-essential amino acids (NEAA, Thermofisher Scientific), penicillin/streptomycin mix (R\&D systems) and growth factors; $20 \mathrm{ng} / \mathrm{mL}$ recombinant human epidermal growth factor (EGF, R\&D Systems, Minneapolis, MN, USA) and $20 \mathrm{ng} / \mathrm{mL}$ recombinant human basic fibroblast growth factor (bFGF, R\&D Systems). For the differentiation of hVM1 cells, growth medium was replaced with differentiation medium. The differentiation medium contained the same components as growth medium besides EGF and bFGF, which were replaced by differentiation factors; $2 \mathrm{ng} / \mathrm{mL}$ glial cell-line derived neurotrophic factor (GDNF, PeproTech) and $100 \mu \mathrm{M}$ dibutyryl-cyclic adenosine monophosphate (dbcAMP, Sigma Aldrich) factor. The differentiation protocol started with $24 \mathrm{~h}$ of cell culture with growth medium and after $24 \mathrm{~h}$, growth medium was replaced with a fresh differentiation medium. The differentiation medium was then replaced with a $2 / 3$ fresh differentiation medium every other day. The differentiation was carried out for 10 days and cultures were then analyzed with ICC and SEM.

\section{Scanning electron microscopy of hNSCs on carbon nanograss}

Carbon structures and cells growing/differentiating on different substrates were imaged with a Carl Zeiss Auriga microscope. 3D-views of the CNG structures were captured at a tilting angle of $30^{\circ}$. Cells were fixed in $2 \%$ of glutaraldehyde diluted in phosphate buffer saline (PBS) 


\section{WILEY-VCH}

solution for 1-hour and were rinsed once with phosphate buffer (PB) for 15 mins and twice with PBS followed by one-time water rinsing for 15 mins. Samples were then dehydrated with a sequence of ethanol-water solutions ranging from $10 \%$ to $100 \%$ of ethanol.

\section{Immunocytochemistry (ICC)}

The differentiated hNSCs were immunostained for $\beta$-III-tubulin (represented as TUBB3: a biomarker that identifies neuronal cytoskeleton proteins), Tyrosine Hydroxylase (represented as $\mathrm{TH}$; the rate-limiting enzyme of catecholamine biosynthesis, identifying DAn) and the cell nuclei (represented by DAPI, a DNA intercalating probe).

Cells were fixed for 20 mins with 4\% paraformaldehyde in PBS solution (ICC buffer, Thermofisher Scientific) 3-days after plating in case of growing cell cultures, and 10-days in case of differentiating cell cultures. Samples were then rinsed thrice for 15 minutes with PBS and blocked for 2-hours in 5\% goat (Gibco) and 5\% horse serum (Gibco) with $0.5 \%$ Triton (X100, Merck) in PBS to permeabilize cell membranes and block unspecific binding of antibodies. This was followed by overnight incubation at $4{ }^{\circ} \mathrm{C}$ with primary antibodies: rabbit polyclonal antibody against Tyrosine Hydroxylase, TH (1:500; Pel-Freez \#P40101-0) and mouse monoclonal antibody against $\beta$-III-tubulin, TUBB3 (1:500; Sigma \#T8660). Next day, samples were rinsed thrice with $0.5 \%$ Triton in PBS solution followed by 2-hours incubation with secondary antibodies: (i) anti-rabbit Alexa-647 (1:500; Life Tech \#A21245), (ii) anti-mouse Alexa-546 (1:500; Life Tech \#A11030) and DAPI (1:1000; Thermofisher Scientific \#D1306) at room temperature. The choice of fluorochromes was made to avoid interference with the endogenous GFP expression in the hVM1-BclX $\mathrm{L}_{\mathrm{L}}$ cells. ${ }^{[48]}$ Finally, the samples were rinsed with $0.5 \%$ Triton in PBS, $0.3 \%$ Triton in PBS and last with PBS, mounted with Mowiol antifading reagent, and dried for 24 hours prior to fluorescence microscopy. 


\section{WILEY-VCH}

\section{Image and data analysis of cell-cultures and differentiation}

Microphotography of immuno-stained cultures and differentiation samples on all substrates was carried out on an upright fluorescent microscope (Zeiss: Axiovert200 inverted microscope invivo system coupled to a monochrome sCMOS camera) with 20x objective (20x /0.5: PlanNeofluar. Field clear (H) and Nomarski (DIC II) using Metamorph software. Image analyses were performed using Fiji NIH image analysis software. Statistical tests were run using GraphPad Prism statistics software, with results shown as the mean \pm standard error of the mean (S.E.M) of data with $n=3$ for three independent experiments.

\section{Quantification of cell morphology}

Five independent trials with three replicates each were assessed using Fiji image analysis software for individual cell morphology of hNSCs that were seeded and differentiated for ten days. FC substrates were used as the control for this analysis. Three different morphological parameters were taken into consideration for quantification of cell morphology: (i) area, (ii) elongation and (iii) circularity. Elongation and circularity were measured as [aspect ratio: i.e.,

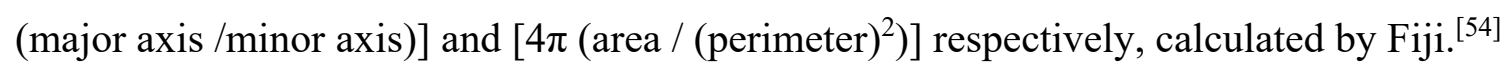

\section{RNA extraction and expression analysis}

Total RNA extraction was carried out with Direct-zol RNA MiniPrep Plus kit (ZYMO Research) following manufacturer's instructions. RT reactions were performed using Super Script IV VILO Master Mix (ThermoFisher-Invitrogen). SsoFast ${ }^{\mathrm{TM}}$ EvaGreen ${ }^{\circledR}$ Supermix, (Bio-Rad) reagent was used for qPCR expression profiling, carried out in a CFX384 Real Time System C1000 Thermal Cycler (Bio-Rad), in hard-Shell® 384-Well PCR Plates White Well Clear shell (Bio-Rad). ValidPrime ${ }^{\circledR}$ assay was performed to control the presence of genomic DNA background signal during qPCR expression profiling (Figure S1A-C (Supporting Information)). Relative quantification was performed using the 2-ddCq method (Figure S1D 


\section{WILEY-VCH}

(Supporting Information)), using as reference gene HPRT and as calibrator TCP sample. Statistical analysis was carried out with GraphPad Prism statistical software ( $n=3$ biological replicates). The same cDNA samples used for qPCR profiling were analyzed by endpoint RTPCR. PCR was carried out using Platinum ${ }^{\mathrm{TM}}$ Taq DNA Polymerase (Invitrogen) in a 2720 Thermal Cycler (Applied Biosystems).

\section{Western blot analysis}

Denatured total protein extract from the different samples was loaded on Any KD precast polyacrylamide gel (Bio-Rad) and transferred to nitrocellulose membranes using Trans-Blot Turbo Mini Nitrocellulose ready-to-use transfer Packs (Bio-Rad). Blots were incubated overnight at $4^{\circ} \mathrm{C}$ with primary antibodies dilution, for 2 hours at room temperature with HRPconjugated secondary antibodies (1:2000), (Figure S2 (Supporting Information)). Detection was carried out using ECL ${ }^{\mathrm{TM}}$ Western Blotting Reagents (GE Life Sciences) and signal detection and acquisition was carried out in an Amersham Imager 680 blot gel imager [AI680] (GE Life Sciences). The primary antibodies used are as follows: 1) Rabbit Anti-Tyrosine Hydroxylase Antibody (TH), 1:1000 (Pel-Freez \#P40101-0), 2) Rabbit Anti- Glial Fibrillary Acidic Protein (GFAP), 1:2000 (Dako \#Z0334), 3) Goat Anti-Doublecortin antibody (C-18) (DCX), 1:1000 (Santa Cruz \#sc-8066), 4) Mouse monoclonal Anti- $\beta$-Actin antibody (ACTB), 1:1000 (Sigma \#A5441). For western blot quantitation, data from bands and their background acquisition was performed using ImageJ software. Blots were normalized to the loading control, and final results were calculating using TCP as control sample. Statistical t-test analysis was carried out with GraphPad Prism statistical software ( $\mathrm{n}=3$ biological replicates).

\section{Supporting Information}

Supporting Information is available from the Wiley Online Library or from the author. 


\section{WILEY-VCH}

\section{Acknowledgements}

The work at DTU was supported by Marie-Skłodowska-Curie Horizon-2020 Innovative Training Network (H2020-MSCA-ITN-2016) with the grant agreement number: 722779. Work at the CBMSO was supported by grants (to AMS) SAF-2017-83241-R, RETICS TerCel RD16/0011/0032. We are especially thankful to the CBMSO Microscopy Service (SMOC) and IMDEA Nanosciences (SEM). qPCR experimental development and data analysis support were provided by the Genomics and NGS Core Facility at the Centro de Biología Molecular Severo Ochoa (CBMSO, CSIC-UAM), Madrid, Spain.

Received: ((will be filled in by the editorial staff))

Revised: ((will be filled in by the editorial staff)) Published online: ((will be filled in by the editorial staff))

\section{References}

[1] F. Berthiaume, T. J. Maguire, M. L. Yarmush, Annu. Rev. Chem. Biomol. Eng. 2011, 2, 403.

[2] M. Politis, O. Lindvall, BMC Med. 2012, 10.

[3] A. K. Meyer, M. Maisel, A. Hermann, K. Stirl, A. Storch, J. Neurol. Sci. 2009, 289, 93.

[4] M. Parmar, Development 2018, 145, dev156117.

[5] R. A. Barker, M. Parmar, L. Studer, J. Takahashi, Cell Stem Cell 2017, 21, 569.

[6] https://www.clinicaltrials.gov/.

[7] M. Parmar, S. Grealish, C. Henchcliffe, Nat. Rev. 2020, 21, 103.

[8] A. Villa, I. Liste, E. T. Courtois, E. G. Seiz, M. Ramos, M. Meyer, B. Juliusson, P. Kusk, A. Martínez-Serrano, Exp. Cell Res. 2009, 315, 1860.

[9] N. Ni, Y. Hu, H. Ren, C. Luo, P. Li, PLoS One 2013, 8, 84504.

[10] W. Chen, Y. Shao, X. Li, G. Zhao, J. Fu, Nano Today 2014, 9, 759. 


\section{WILEY-VCH}

[11] M. Ventre, C. F. Natale, C. Rianna, P. A. Netti, J. R. Soc., Interface 2014, 11, 20140687.

[12] K. Kulangara, A. F. Adler, H. Wang, M. Chellappan, E. Hammett, R. Yasuda, K. W. Leong, Biomaterials 2014, 35, 5327.

[13] X. Yao, R. Peng, J. Ding, Adv. Mater. 2013, 25, 5257.

[14] O. P. Hamill, B. Martinac, Physiol. Rev. 2001, 81, 685.

[15] D.-H. Kim, P. K. Wong, J. Park, A. Levchenko, Y. Sun, Annu. Rev. Biomed. Eng. 2009, 11, 203.

[16] J. Eyckmans, T. Boudou, X. Yu, C. S. Chen, Dev. Cell 2011, 21, 35.

[17] S. Xie, R. Luttge, Microelectron. Eng. 2014, 124, 30.

[18] P. Zorlutuna, N. Annabi, G. Camci-Unal, M. Nikkhah, J. M. Cha, J. W. Nichol, A. Manbachi, H. Bae, S. Chen, A. Khademhosseini, Adv. Mater. 2012, 24, 1782.

[19] E. Carletti, A. Motta, C. Migliaresi, In 3D Cell Culture: Methods and Protocols; 2011; pp. 17-39.

[20] S. Oh, K. S. Brammer, Y. S. J. Li, D. Teng, A. J. Engler, S. Chien, S. Jin, Proc. Natl. Acad. Sci. 2009, 106.

[21] M. A. Bucaro, Y. Vasquez, B. D. Hatton, J. Aizenberg, ACS Nano 2012, 6, 6222.

[22] K. S. Beckwith, S. P. Cooil, J. W. Wells, P. Sikorski, RSC Nanoscale 2015, 7, 8438.

[23] J. Fu, Y.-K. Wang, M. T. Yang, R. A. Desai, X. Yu, Z. Liu, C. S. Chen, Nat. Methods $2010,7,733$

[24] S. Bonde, N. Buch-Månson, K. R. Rostgaard, K. Andersen, T. Berthing, K. L. Martinez, Nanotechnology 2014, 25, 362001.

[25] N. R. Blumenthal, O. Hermanson, B. Heimrich, V. P. Shastri, Proc. Natl. Acad. Sci. 2014, 111, 16124.

[26] S. P. Khan, G. G. Auner, G. M. Newaz, Nanomedicine Nanotechnology, Biol. Med. $\mathbf{2 0 0 5}, 1,125$ 


\section{WILEY-VCH}

[27] Y. W. Fan, F. Z. Cui, S. P. Hou, Q. Y. Xu, L. N. Chen, I.-S. Lee, J. Neurosci. Methods 2002, $120,17$.

[28] Carbon Nanomaterials for Biomedical Applications; Zhang, M.; Naik, R. R.; Dai, L., Eds.; Springer Series in Biomaterials Science and Engineering; Springer International Publishing: Cham, 2016; Vol. 5.

[29] M. Mohajeri, B. Behnam, A. Sahebkar, J. Cell. Physiol. 2019, 234, 298.

[30] S.-Z. Yow, T. H. Lim, E. K. F. Yim, C. T. Lim, K. W. Leong, S.-Z. Yow, T. H. Lim, E. K. F. Yim, C. T. Lim, K. W. Leong, Polymers (Basel). 2011, 3, 527.

[31] S. Ryon Shin, S. Mi Jung, M. Zalabany, K. Kim, P. Zorlutuna, S. bok Kim, M. Nikkhah, M. Khabiry, M. Azize, J. Kong, K. Wan, T. Palacios, M. R. Dokmeci, H. Bae, X. Tang, A. Khademhosseini, ACS Nano 2013, 7, 2369.

[32] N. Li, Q. Zhang, S. Gao, Q. Song, R. Huang, L. Wang, L. Liu, J. Dai, M. Tang, G. Cheng, Sci. Rep. 2013, 3, 1604.

[33] M. R. Abidian, E. D. Daneshvar, B. M. Egeland, D. R. Kipke, P. S. Cederna, M. G. Urbanchek, Adv. Healthcare. Mater. 2012, 1, 762.

[34] L. Amato, A. Heiskanen, C. Caviglia, F. Shah, K. Zór, M. Skolimowski, M. Madou, L. Gammelgaard, R. Hansen, E. G. Seiz, M. Ramos, T. R. Moreno, A. Martínez-Serrano, S. S. Keller, J. Emnéus, Adv. Funct. Mater. 2014, 24, 7042.

[35] S. Hemanth, C. Caviglia, S. S. Keller, Carbon 2017, 121, 226.

[36] Y. M. Hassan, C. Caviglia, S. Hemanth, D. M. A. Mackenzie, T. S. Alstrøm, D. H. Petersen, S. S. Keller, J. Anal. Apllied Pyrolysis 2017, 125, 91.

[37] M. Muthuraman, N. Koirala, D. Ciolac, B. Pintea, M. Glaser, S. Groppa, G. Tamás, S. Groppa, G. Tamás, S. Groppa, Front. Neurol. 2018, 9, 711.

[38] E. Peltola, J. J. Heikkinen, K. Sovanto, S. Sainio, A. Aarva, S. Franssila, V. Jokinen, T. Laurila, J. Mater. Chem. B 2017, 5, 9033.

[39] S. Vasudevan, J. Kajtez, A. Bunea, A. Gonzalez-Ramos, T. Ramos-Moreno, A. 


\section{WILEY-VCH}

Heiskanen, M. Kokaia, N. B. Larsen, A. Martínez-Serrano, S. S. Keller, J. Emnéus, Adv. Sci. 2019, 6, 1902011.

[40] G. M. Jenkins, A. Jenkins, K. Kawamura, Polymeric carbons: carbon fibre, glass and char; Cambridge University Press, 1976.

[41] O. J. A. Schueller, S. T. Brittain, G. M. Whitesides, Adv. Mater. 1997, 9, 477.

[42] C. Wang, M. Madou, Biosens. Bioelectron. 2005, 20, 2181.

[43] F. L. M. De Volder, R. Vansweevelt, P. Wagner, D. Reynaerts, C. Van Hoof, A. John Hart, ACS Nano 2011, 5, 6593.

[44] R. Du, S. Ssenyange, M. Aktary, M. T. McDermott, Small 2009, 5, 1162.

[45] H. Xu, K. Malladi, C. Wang, L. Kulinsky, M. Song, M. Madou, Biosens. Bioelectron. 2008, 23, 1637.

[46] J. Mitra, S. Jain, A. Sharma, B. Basu, Carbon 2013, 65, 140.

[47] C. Krabbe, E. Courtois, P. Jensen, J. R. Jørgensen, J. Zimmer, A. Martínez-Serrano, M. Meyer, J. Neurochem. 2009, 110, 1908.

[48] E. T. Courtois, C. G. Castillo, E. G. Seiz, M. Ramos, C. Bueno, I. Liste, A. MartínezSerrano, J. Biol. Chem. 2010, 285, 9881.

[49] J. Tønnesen, E. Gonzalez Seiz, M. Ramos, O. Lindvall, A. Martinez-Serrano, M. Kokaia, Exp. Neurol. 2010, 223, 653.

[50] E. G. Seiz, M. Ramos-Gómez, E. T. Courtois, J. Tønnesen, M. Kokaia, I. Liste Noya, A. Martínez-Serrano, Exp. Cell Res. 2012, 318, 2446.

[51] C. Krabbe, S. T. Bak, P. Jensen, C. Von Linstow, M.-A. Serrano, C. Hansen, M. Meyer, PLoS One 2014, 9, 96465.

[52] A. Martínez-Serrano, M. P. Pereira, N. Avaliani, A. Nelke, M. Kokaia, T. RamosMoreno, Cell Transplant. 2016, 25, 2083.

[53] K. H. Rasmussen, S. S. Keller, F. Jensen, A. M. Jorgensen, O. Hansen, Microelectron. Eng. 2013, 112, 35 . 


\section{WILEY-VCH}

[54] F. Viela, D. Granados, A. Ayuso-Sacido, I. Rodríguez, Adv. Funct. Mater. 2016, 26, 5599.

[55] K. V. Nemani, K. L. Moodie, J. B. Brennick, A. Su, B. Gimi, Mater. Sci. Eng. C 2013, $33,4453$.

[56] S.-H. Cho, H. M. Lu, L. Cauller, M. I. Romero-Ortega, J.-B. Lee, G. A. Hughes, IEEE Sens. J. 2008, 8, 1830.

[57] M. Hennemeyer, F. Walther, S. Kerstan, K. Schürzinger, A. M. Gigler, R. W. Stark, Microelectron. Eng. 2008, 85, 1298.

[58] P. Xue, J. Bao, Y. J. Chuah, N. V Menon, Y. Zhang, Y. Kang, Langmuir 2014, 30, 3110.

[59] C. Argentati, F. Morena, I. Tortorella, M. Bazzucchi, S. Porcellati, C. Emiliani, S. Martino, Int. J. Mol. Sci. 2019, 20, 5337.

[60] C. Simitzi, K. Karali, A. Ranella, E. and Stratakis, ChemPhysChem 2018, 19, 1143. 


\section{WILEY-VCH}

A) Photolithography

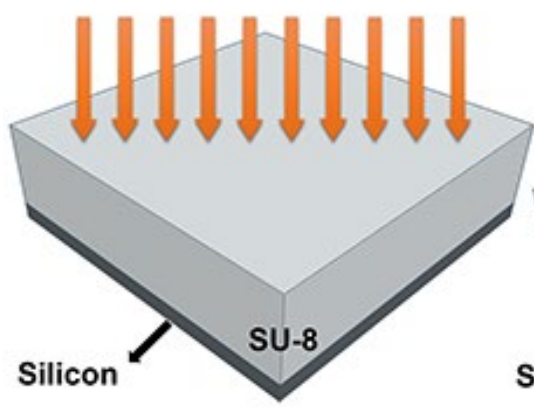

B) Reactive Ion Etching

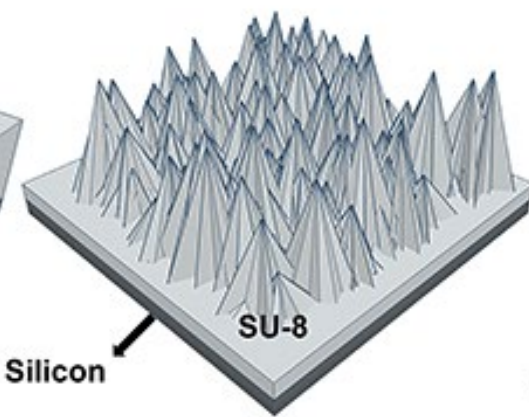

C) Pyrolysis

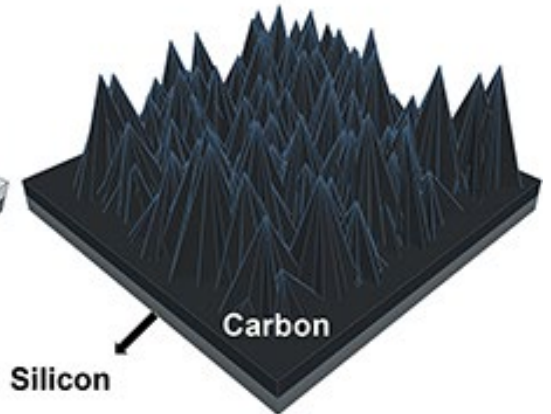

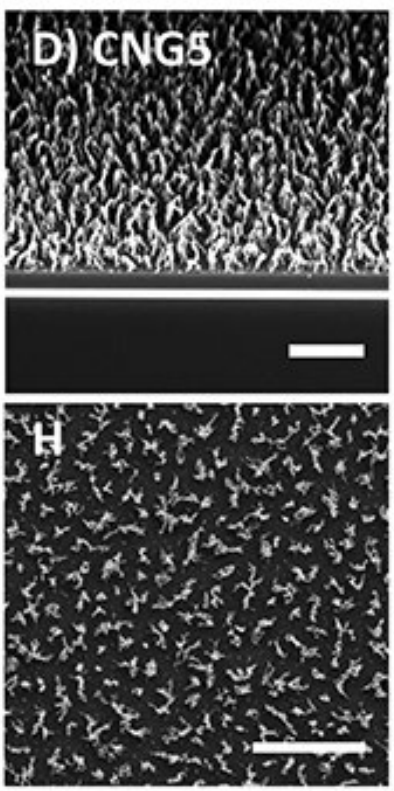

$\mathbf{L}$

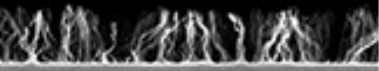
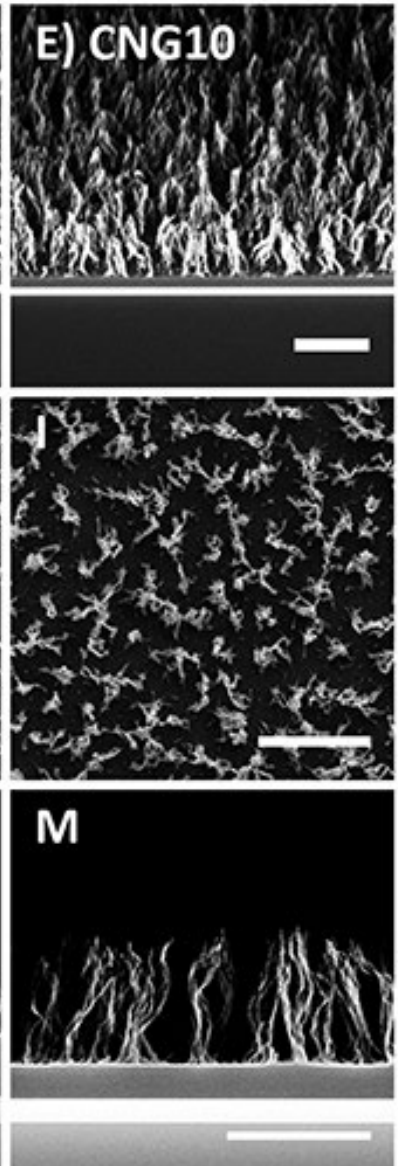
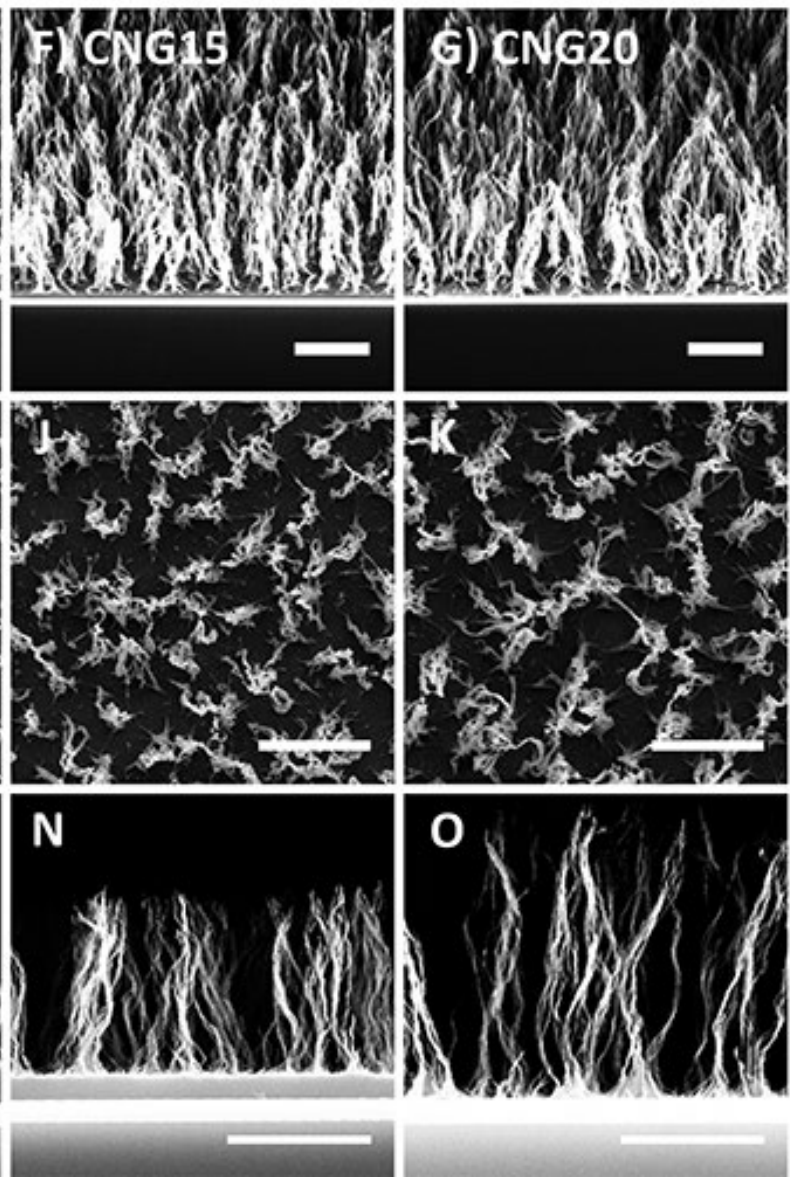

Figure 1. Schematic view of fabrication process of carbon nanograss (CNG) structures using three main steps; A) one step UV photolithography, B) etching polymerized resist layer by reactive ion etching to obtain SU-8 nanograss, C) pyrolyzing the polymer grass patterns into their respective CNG patterns by pyrolysis. Scanning electron microscopy images of all four designs of fabricated CNG structures with 5, 10, 15 and 20 mins etch time from left to right (CNG5, CNG10, CNG15, and CNG20), (D-G) tilted view, (H-K) top view, and (L-O) crosssectional view. Scale bars $5 \mu \mathrm{m}$. 


\section{WILEY-VCH}

Table 1. Physical characteristics of flat carbon (FC) and CNG structures. Data are shown as the mean with \pm standard deviation $n=15$ for height, interspace, and bottom bulk layer thickness and $n=4$ for water contact angle (WCA) measurements.

\begin{tabular}{|c|c|c|c|c|c|}
\hline Topographies & CNG Height & $\begin{array}{c}\text { CNG Cluster } \\
\text { Interspace } \\
{[\mu \mathrm{m}]}\end{array}$ & $\begin{array}{c}\text { Bulk Carbon } \\
\text { Thickness } \\
{[\mu \mathrm{m}]}\end{array}$ & $\begin{array}{c}\text { WCA before } \\
\text { plasma } \\
\left.{ }^{\circ}\right]\end{array}$ & $\begin{array}{c}\text { WCA after } \\
\text { plasma } \\
{\left[^{\circ}\right]}\end{array}$ \\
\hline $\mathrm{FC}$ & N. A & N. A & $2 \pm 0.03$ & $74.5 \pm 0.5$ & $\mathrm{ND}^{\mathrm{a})}$ \\
\hline CNG5 & $1.5 \pm 0.06$ & $0.7 \pm 0.14$ & $1.5 \pm 0.01$ & $117.0 \pm 0.9$ & ND \\
\hline CNG10 & $3.5 \pm 0.06$ & $1.2 \pm 0.10$ & $0.9 \pm 0.01$ & $124.5 \pm 0.6$ & ND \\
\hline CNG15 & $5.5 \pm 0.17$ & $1.5 \pm 0.13$ & $0.6 \pm 0.01$ & $125.6 \pm 0.8$ & ND \\
\hline CNG20 & $7.5 \pm 0.13$ & $2.0 \pm 0.10$ & $0.1 \pm 0.15$ & $129.9 \pm 0.5$ & ND \\
\hline
\end{tabular}




\section{WILEY-VCH}
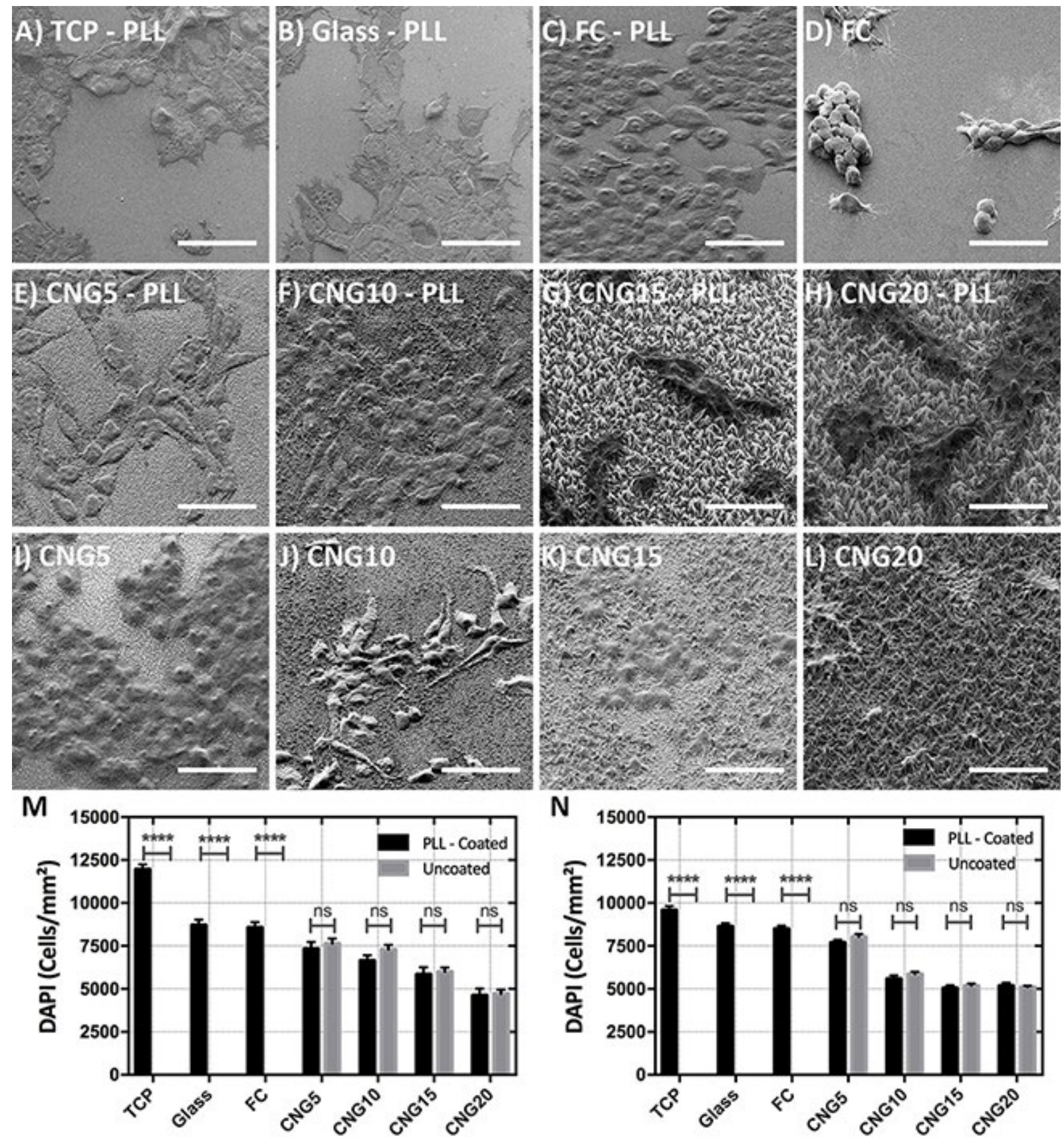

Figure 2. Representative SEMs of hNSCs cultured for 3 days in presence of growth factors (GFs) on: A) PLL coated TCP (the control), B) PLL coated glass (control), C) PLL coated FC, D) uncoated FC, E-H) PLL coated CNG5-20 (representing 5, 10, 15, and 20 min etching time), and, I-L) Uncoated CNG5-20. Scale bars $50 \mu \mathrm{m}$. Comparative analysis of hNSCs viability on all topographies with and without PLL coating for hNSCs; M) growth after 3 days and N) differentiation after 10 days, showing total cells counts obtained from DAPI stained nuclei. The statistical significances $(* * * * P<0.0001, * * * P<0.001)$ after performing two-way ANOVA; Fisher LSD post-hoc test, indicate significant differences between coated and uncoated substrates, while (ns) represents no significance in total cell counts. Error bars show standard error of the mean, $n=3$ independent biological experiments. 


\section{WILEY-VCH}
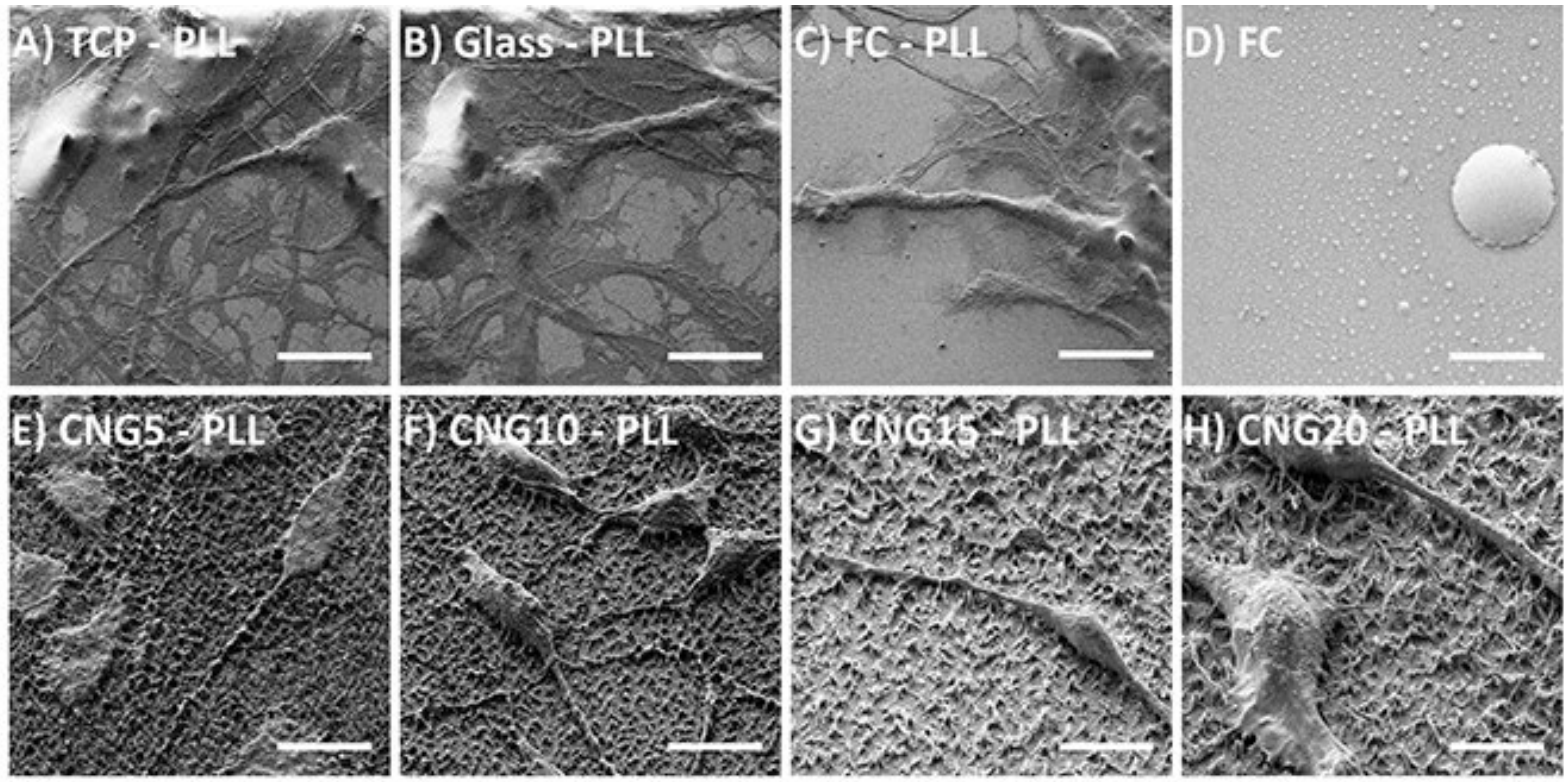

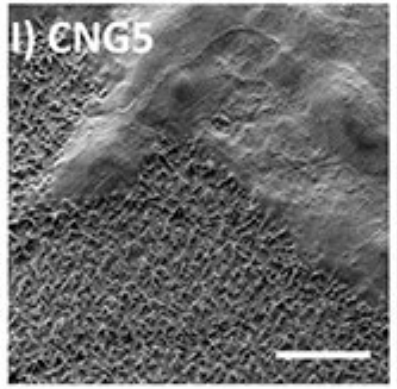

M

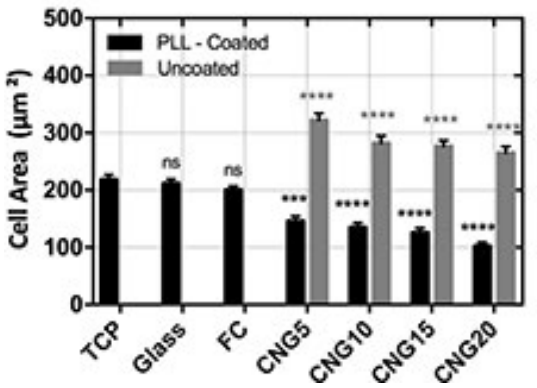

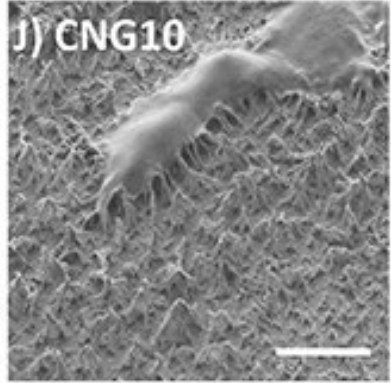

$\mathrm{N}$

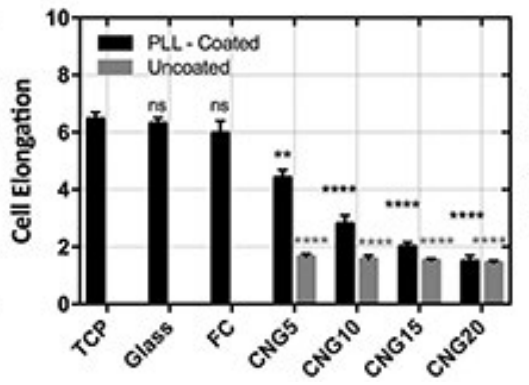

0

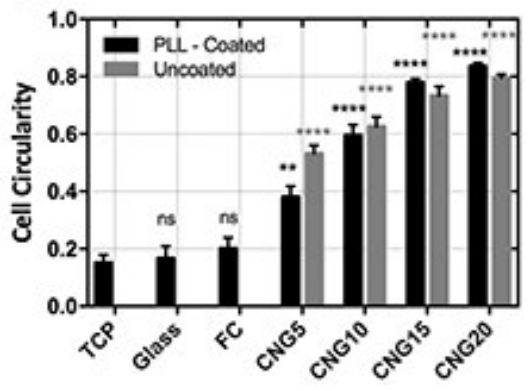

Figure 3. Representative SEM microphotographs of hNSCs differentiated for 10 days in presence of differentiation factors (DFs) on: A) PLL coated TCP (the control), B) PLL coated glass, C) PLL coated FC, D) Uncoated FC showing no cell attachment, E-H) PLL coated CNG5-20 representing 5,10,15, and 20 mins etch time, and I-L) Uncoated CNG5-20 representing 5,10,15, and 20 mins etch time, from left to right respectively. Scale bars $10 \mu \mathrm{m}$. Quantified comparative analysis of cellular morphological parameters in terms of M) cell area, $\mathrm{N})$ cell elongation and $\mathrm{O})$ cell circularity. The statistical significances $(* * * * P<0.0001, * * * P$ $<0.001, * * P<0.01$ and $* P<0.05)$ after performing one-way ANOVA; Dunnett's multiple comparisons test, indicate significant difference for both with and without PLL coated CNGs compared to PLL coated and uncoated FC controls respectively. Error bars represent standard error of the mean, $n=3$ independent biological experiments. 


\section{WILEY-VCH}
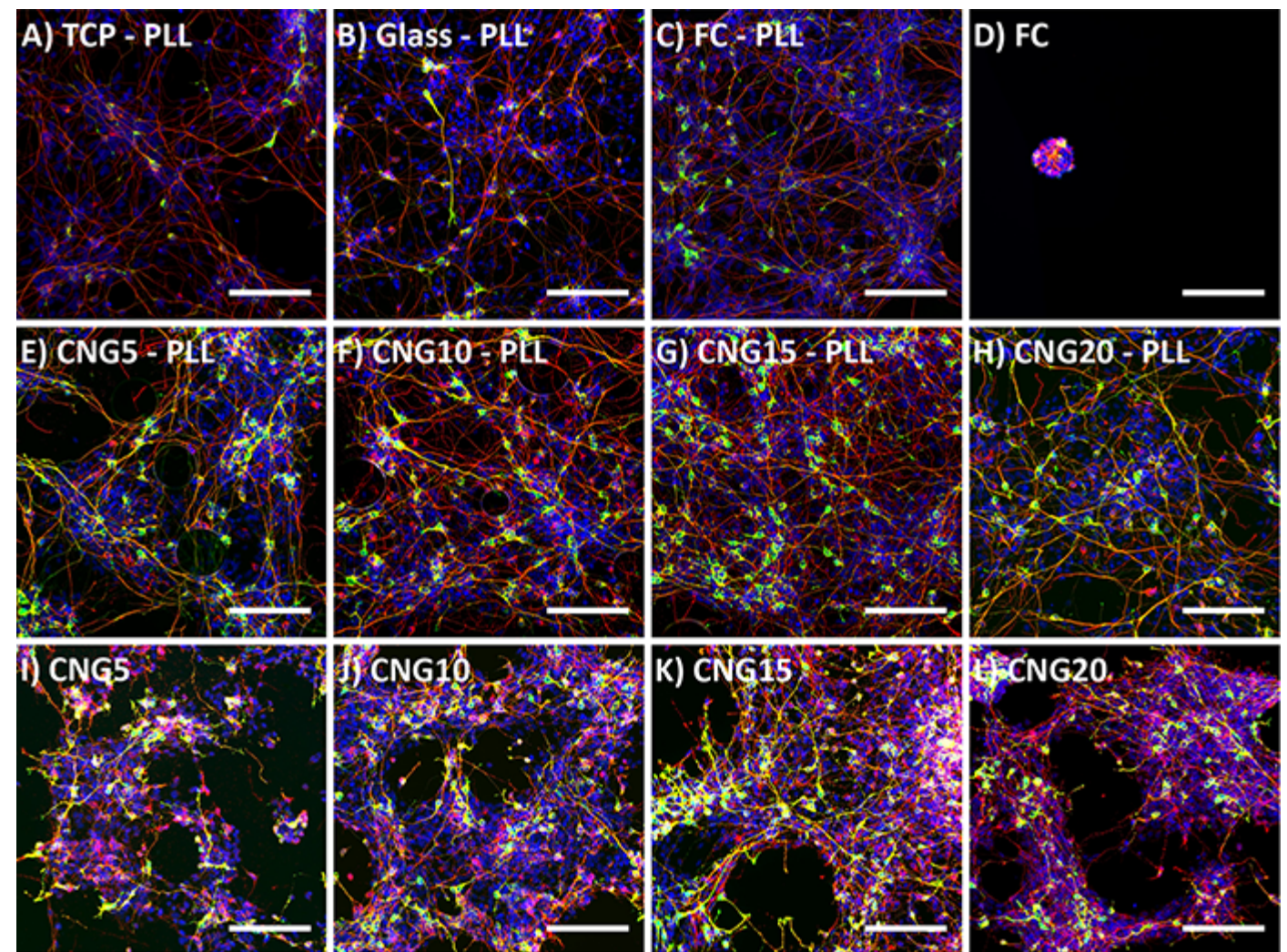

M

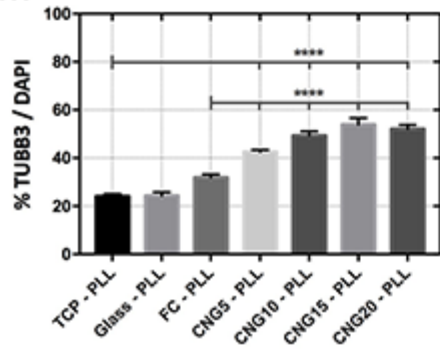

$\mathrm{N}$

$\mathbf{P}$
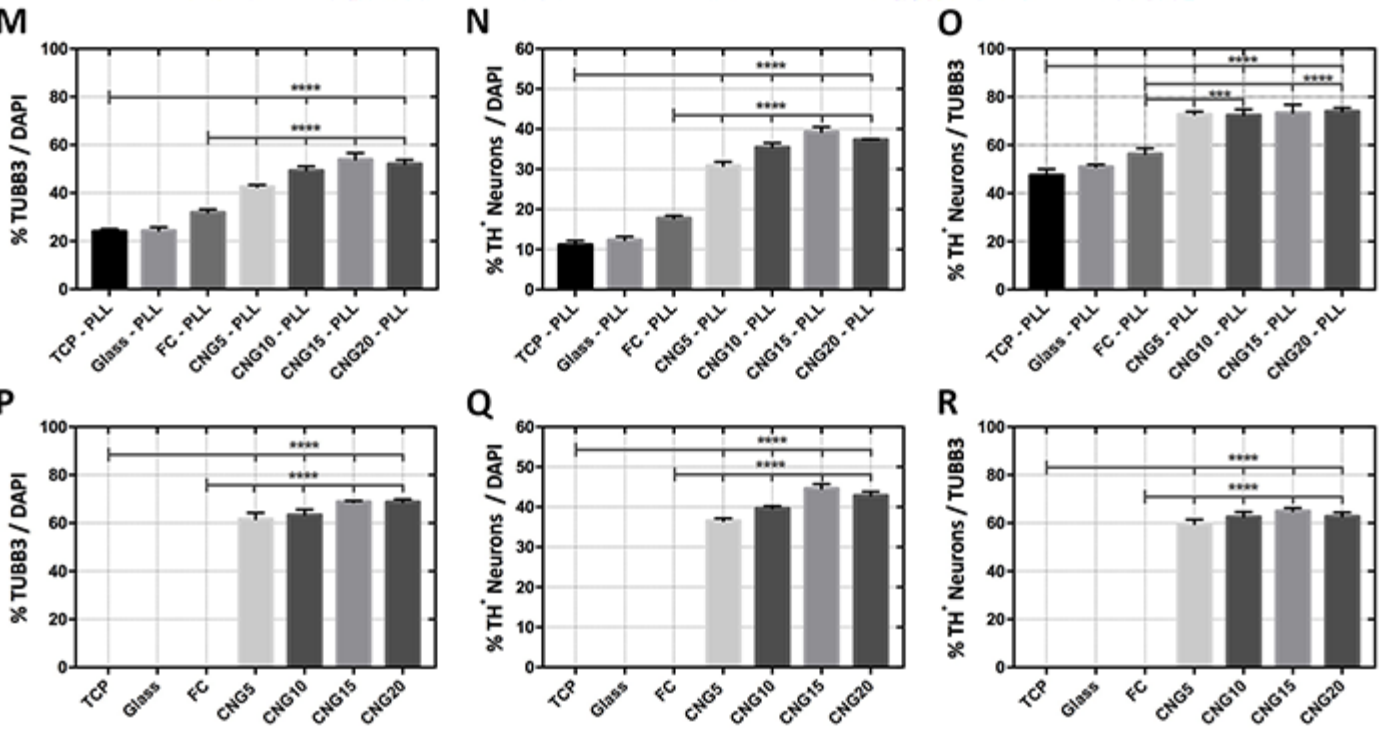

Figure 4. Immunocytochemistry (ICC) characterization of hNSCs differentiated for 10 days in presence of differentiation factors (DF) on A) PLL coated TCP, B) PLL coated glass, C) PLL coated FC, D) Uncoated FC, E-H) PLL coated CNG5-20 representing 5,10,15, and 20 mins etch time, and, I-L) Uncoated CNG5-20 (representing 5,10,15, and 20 mins etch time). Different colors represent TUBB3 (neurons), TH (DAn), and DAPI (nuclei). Scale bars 100 $\mu \mathrm{m}$. Enhanced generation of neurons ( $\mathrm{M}$ and $\mathrm{P})$, DAn from the overall cell population $(\mathrm{N}$ and $\mathrm{Q})$, and DAn from the overall neuronal population (O and $\mathrm{R}$ ) after 10 days of hNSCs differentiation, measured by quantification of cells in immunostained images. The upper row represents results from PLL coated topographies (M-O), and the bottom row shows results for uncoated topographies $(\mathrm{P}-\mathrm{R})$. The statistical significance $(* * * * P<0.0001$ and $* * * P<0.001)$ after performing one-way ANOVA followed by Dunnett's multiple comparisons test, indicates significant differences for FC and CNG compared to TCP control, and CNG compared to FC. Error bars represent standard error of mean, $n=3$. 


\section{WILEY-VCH}

\section{The table of contents Caption}

The cover art shows the concept of the work presented in the paper that pyrolytic carbon nanograss (CNG) enhances hNSCs neurogenesis up to 2.3 folds and DAn differentiation up to 3.5 folds as compared to the tissue culture plastic control.

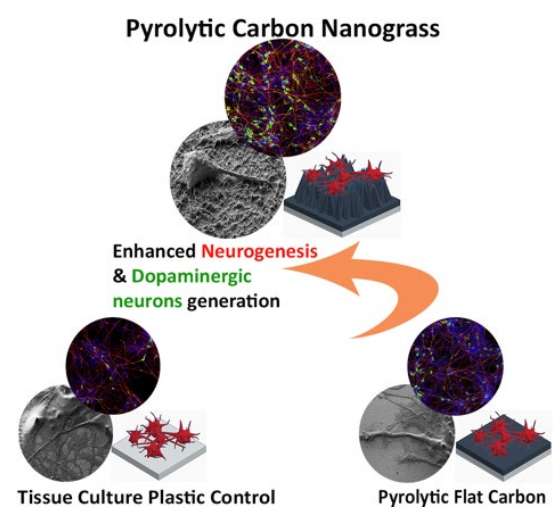

Keyword: Pyrolytic Carbon Nanograss for Human neural stem cells

A. Asif, Dr. A. Heiskanen, Prof. J. Emnéus

Department of Biotechnology and Biomedicine (DTU Bioengineering)

Produktionstorvet, Building 423, Room 122, 2800 Kgs. Lyngby, Denmark

E-mail: jemn@dtu.dk

Dr. S.S. Keller

National Centre for Nano Fabrication and Characterization (DTU Nanolab)

Ørsteds Plads, Building 347, 2800 Kgs. Lyngby, Denmark

Dr. S. Gracía-López, Dr. M. Pereira, Prof. A. Martínez-Serrano

Molecular Neuropathology, Center of Molecular Biology Severo Ochoa (UAM-CSIC).

Nicolás Cabrera 1, 28049-Madrid. Spain

\section{Title}

Pyrolytic Carbon Nanograss Enhances Neurogenesis and Dopaminergic Differentiation of Human Midbrain Neural Stem Cells 


\section{WILEY-VCH}

Copyright WILEY-VCH Verlag GmbH \& Co. KGaA, 69469 Weinheim, Germany, 2018.

\section{Supporting Information}

\section{Title}

Pyrolytic Carbon Nanograss Enhances Neurogenesis and Dopaminergic Differentiation of Human Midbrain Neural Stem Cells

Afia Asif, Dr. Silvia Gracía-López, Dr. Arto Heiskanen, Prof. Alberto Martínez-Serrano, Dr. Stephan S. Keller, Dr. Marta Pereira, Prof. Jenny Emnéus

A. Asif, Dr. A. Heiskanen, Prof. J. Emnéus

Department of Biotechnology and Biomedicine (DTU Bioengineering)

Produktionstorvet, Building 423, Room 122, 2800 Kgs. Lyngby, Denmark

E-mail: jemn@dtu.dk

Dr. S.S. Keller

National Centre for Nano Fabrication and Characterization (DTU Nanolab)

Ørsteds Plads, Building 347, 2800 Kgs. Lyngby, Denmark

Dr. S. Gracía-López, Dr. M. Pereira, Prof. A. Martínez-Serrano

Molecular Neuropathology, Center of Molecular Biology Severo Ochoa (UAM-CSIC).

Nicolás Cabrera 1, 28049-Madrid. Spain 


\section{WILEY-VCH}

Table S1. Water contact angles measurements before and after oxygen plasma on flat carbon (FC) carbon nanograss (CNGs).

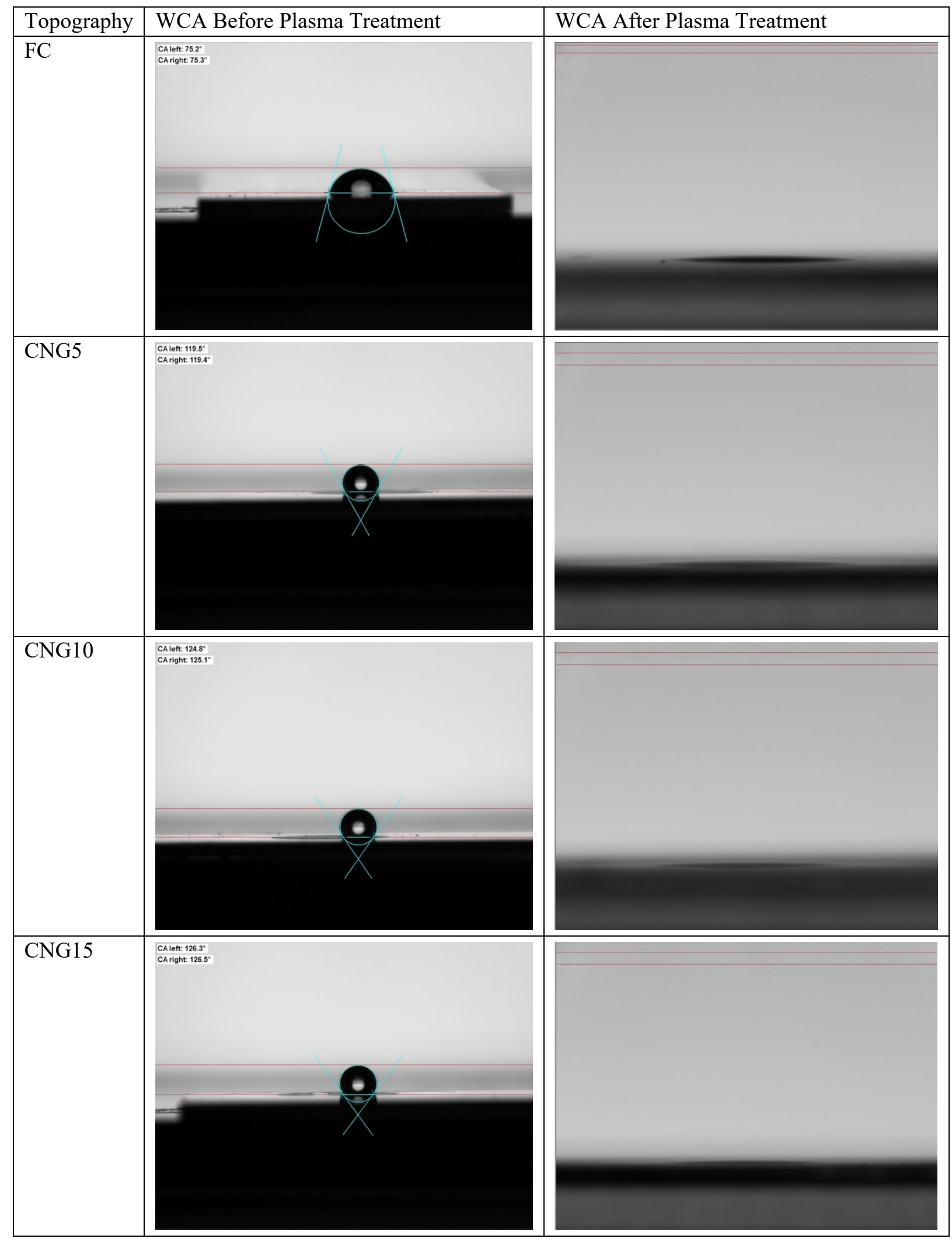




\section{WILEY-VCH}
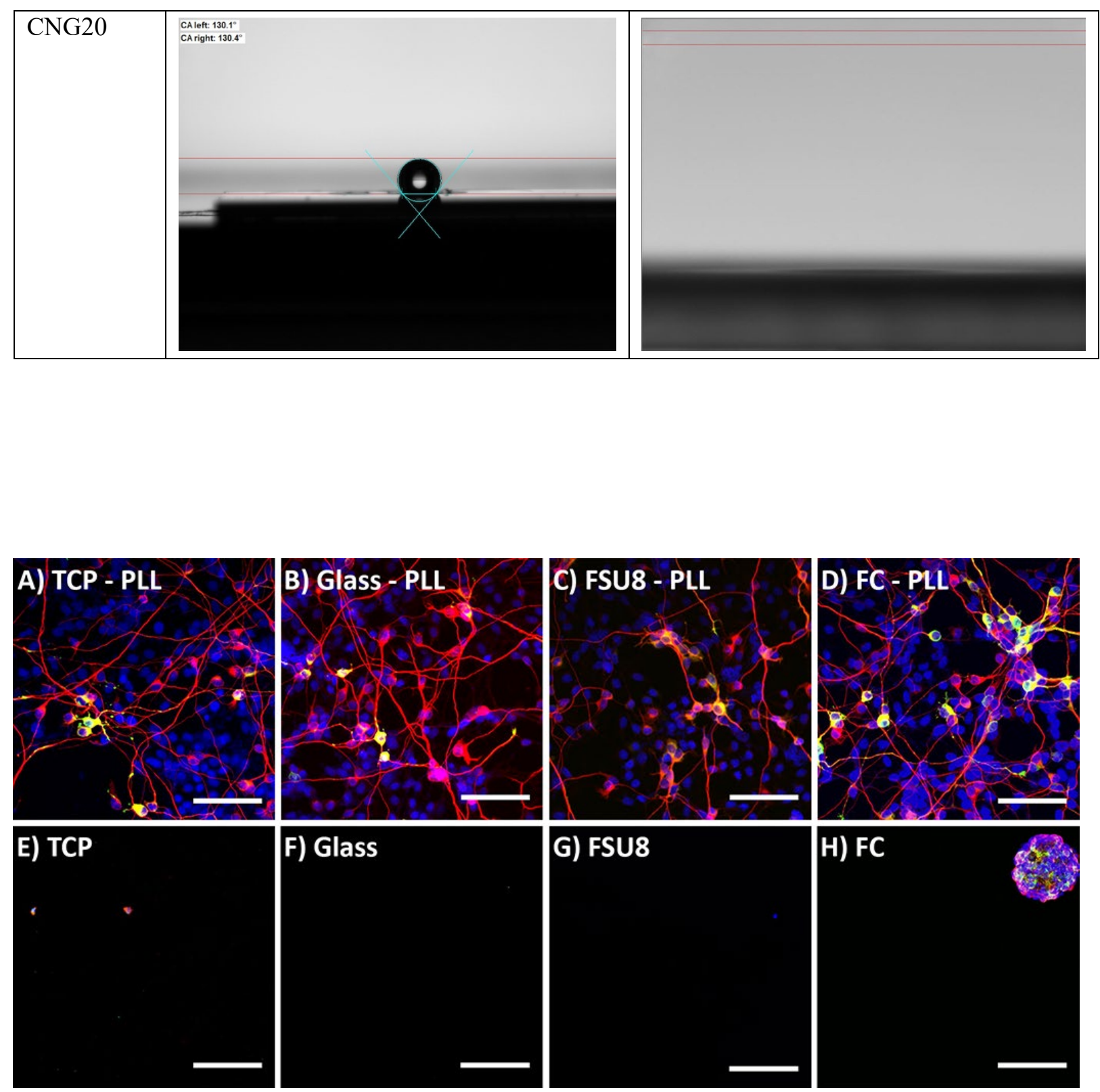

Figure S1. ICC characterization of hNSCs differentiation (10 days) for neurogenesis and DAn generation for PLL coated flat surfaces (A-D), and uncoated flat surfaces (E-H). Results show that hNSCs do not adhere to flat substrates in absence of PLL, while hNSCs adhesion, viability and maturation on flat PLL coated substrates support hNSCs differentiation. Moreover, PLL coated FC clearly shows more DAn generation in comparison to PLL coated TCP control. Scale bars $100 \mu \mathrm{m}$. TUBB3 (neurons), TH (DAn), and DAPI (nuclei). 
Table S2. Fold increase in neurogenesis (TUBB3), DA neurogenesis from entire population $\left(\mathrm{TH}^{+} / \mathrm{DAPI}\right)$ and DA neurogenesis from entire neuronal population $\left(\mathrm{TH}^{+} / \mathrm{TUBB} 3\right)$ on PLLcoated CNG topographies w.r.t PLL-coated TCP control.

\begin{tabular}{lccc}
\hline $\begin{array}{c}\text { PLL-coated } \\
\text { Topographies }\end{array}$ & $\begin{array}{c}\text { TUBB3 } \\
\text { Increase } \\
\text { [Folds] }\end{array}$ & $\begin{array}{c}\mathrm{TH}^{+} / \mathrm{DAPI} \\
\text { Increase } \\
\text { [Folds] }\end{array}$ & $\begin{array}{c}\mathrm{TH}^{+} / \mathrm{TUBB3} \\
\text { Increase } \\
\text { [Folds] }\end{array}$ \\
\hline TCP & - & - & - \\
\hline Glass & 1.1 & 1.1 & 1.1 \\
\hline FC & 1.3 & 1.6 & 1.2 \\
\hline CNG5 & 1.8 & 2.8 & 1.6 \\
\hline CNG10 & 2.0 & 3.2 & 1.5 \\
\hline CNG15 & 2.3 & 3.5 & 1.6 \\
\hline CNG20 & 2.2 & 3.4 & 1.6 \\
\hline
\end{tabular}

Table S3. Fold increase in neurogenesis (TUBB3), DA neurogenesis from entire population $\left(\mathrm{TH}^{+} / \mathrm{DAPI}\right)$ and DA neurogenesis from entire neuronal population $\left(\mathrm{TH}^{+} / \mathrm{TUBB} 3\right)$ on PLLcoated CNG topographies w.r.t PLL-coated FC control.

\begin{tabular}{lccc}
\hline $\begin{array}{c}\text { PLL- coated } \\
\text { Topographies }\end{array}$ & $\begin{array}{c}\text { TUBB3 } \\
\text { Increase } \\
\text { [Folds] }\end{array}$ & $\begin{array}{c}\mathrm{TH}^{+} / \mathrm{DAPI} \\
\text { Increase } \\
\text { [Folds] }\end{array}$ & $\begin{array}{c}\mathrm{TH}^{+} / \mathrm{TUBB} 3 \\
\text { Increase } \\
\text { [Folds] }\end{array}$ \\
\hline FC & - & - & - \\
\hline CNG5 & 1.3 & 1.7 & 1.3 \\
\hline CNG10 & 1.5 & 1.9 & 1.3 \\
\hline CNG15 & 1.7 & 2.1 & 1.3 \\
\hline CNG20 & 1.6 & 2.1 & 1.3 \\
\hline
\end{tabular}

Table S4. Shows fold increase in neurogenesis: TUBB3, dopaminergic differentiation from entire cell population $\mathrm{TH}^{+} / \mathrm{Dapi}$, and dopaminergic neurons from neuronal population $\mathrm{TH}^{+} / \mathrm{TUBB} 3$.

\begin{tabular}{cccc}
\hline $\begin{array}{c}\text { Uncoated } \\
\text { Topographies }\end{array}$ & $\begin{array}{c}\text { TUBB3 } \\
\text { Increase } \\
\text { [Folds] }\end{array}$ & $\begin{array}{c}\text { TH } \\
\text { Increase } \\
\text { [Folds] }\end{array}$ & $\begin{array}{c}\text { TH }^{+} / \text {TUBB3 } \\
\text { Increase } \\
\text { [Folds] }\end{array}$ \\
\hline TCP & No cell adhesion & No cell adhesion & No cell adhesion \\
\hline Glass & No cell adhesion & No cell adhesion & No cell adhesion \\
\hline FC & No cell adhesion & No cell adhesion & No cell adhesion \\
\hline CNG5 & N. A & N. A & N. A \\
\hline CNG10 & N. A & N. A & N. A \\
\hline CNG15 & N. A & N. A & N. A \\
\hline CNG20 & N. A & N. A & N. A
\end{tabular}


A

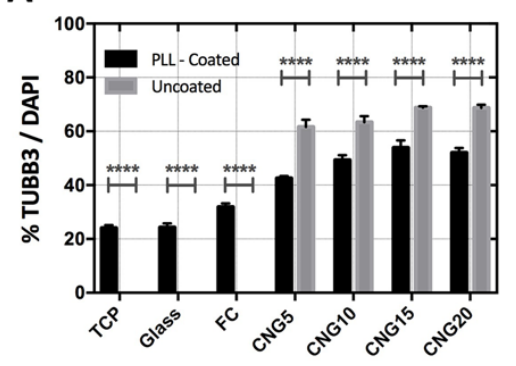

B

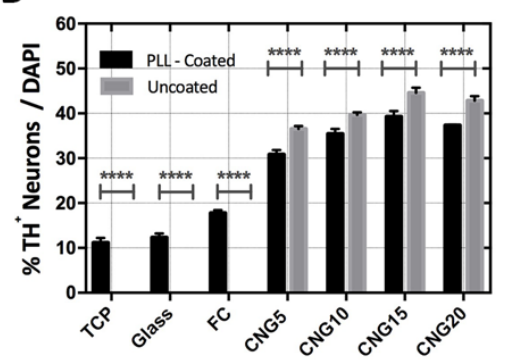

C

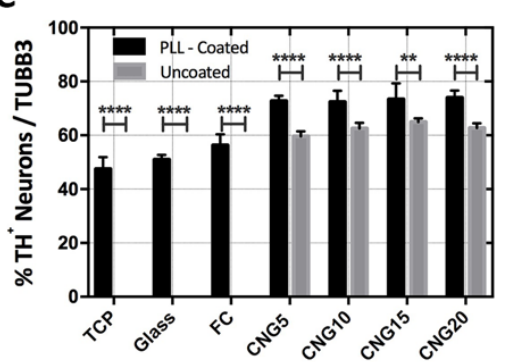

Figure S2. Enhanced generation of neurons (A), DAn from overall cell population (B), and DAn from overall neuronal population $(\mathrm{C})$ on uncoated CNG compared to PLL coated CNG after 10-days hNSCs differentiation show potential of uncoated CNG on hNSCs fate, measured by comparison of uncoated and uncoated substrates with quantification of cell-percentage in immunostained images. The statistical significance $(* * * * P<0.0001$, and $* * P<0.01)$ after performing two-way ANOVA; Fisher LSD post-hoc test, indicates significant differences between coated and uncoated substrates. Error bars represent standard error of mean, $n=3$.

Table S5. Shows fold increase in neurogenesis: TUBB3, DA differentiation from entire cell population $\mathrm{TH}^{+} /$Dapi, and DA neurons from neuronal population $\mathrm{TH}^{+} / \mathrm{TUBB} 3$.

\begin{tabular}{|c|c|c|c|}
\hline Topographies & $\begin{array}{c}\text { Coated Vs Uncoated } \\
\text { TUBB3 } \\
\text { Increase } \\
\text { [Folds] }\end{array}$ & $\begin{array}{c}\text { Coated Vs Uncoated } \\
\mathrm{TH}^{+} / \text {Dapi } \\
\text { Increase } \\
\text { [Folds] }\end{array}$ & $\begin{array}{c}\text { Coated Vs Uncoated } \\
\mathrm{TH}^{+} / \text {TUBB3 } \\
\text { Increase } \\
\text { [Folds] }\end{array}$ \\
\hline TCP & N. A & N. A & N. A \\
\hline Glass & N. A & N. A & N. A \\
\hline $\mathrm{FC}$ & N. A & N. A & N. A \\
\hline CNG5 & 1.5 & 1.2 & 0.8 \\
\hline CNG10 & 1.3 & 1.1 & 0.9 \\
\hline CNG15 & 1.3 & 1.2 & 0.9 \\
\hline CNG20 & 1.3 & 1.2 & 0.9 \\
\hline
\end{tabular}

A

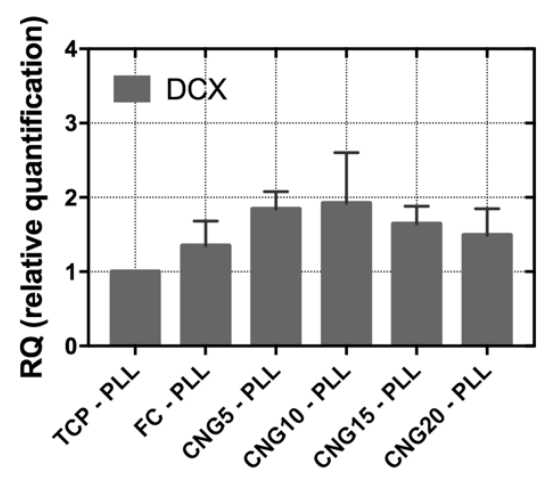

B

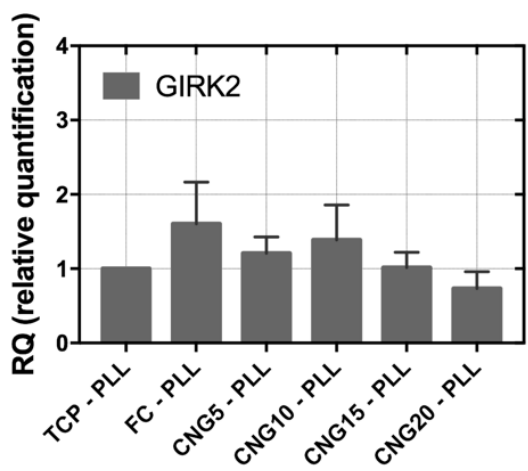

C differentiation

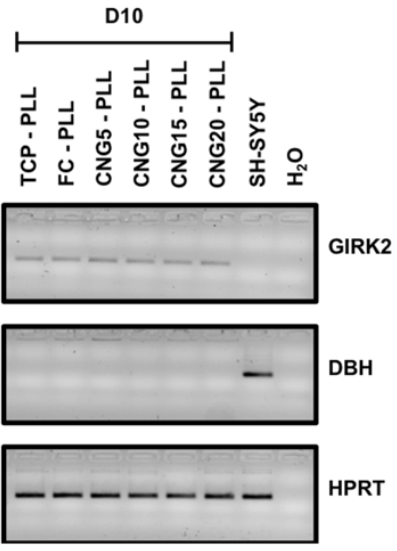

Figure S3. qPCR analysis of: A) immature (DCX) and B) DA (GIRK2) neurons with hNSCs differentiated for 10 days on different PLL coated surfaces ( $n=3$ biological replicates). C) Representative results for RT-PCR analysis of specific genes for DAn (GIRK2) and Non- 


\section{WILEY-VCH}

Adrenergic (NAn) (DBH) neurons resulting from 10 days of differentiation of hNSCs on PLL coated CNG surfaces with TCP as a surface control ( $\mathrm{n}=3$ biological replicates). The SH-SY5Y cell line was used as control for the expression of DBH gene.

A

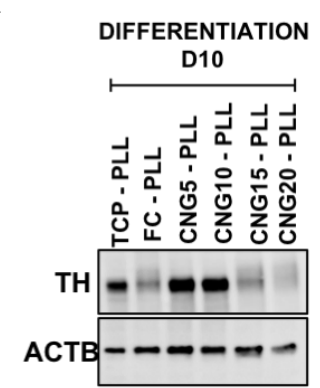

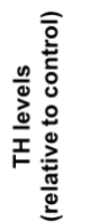

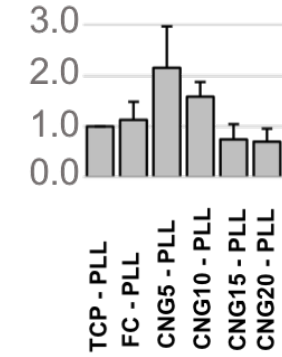

DIFFERENTIATION
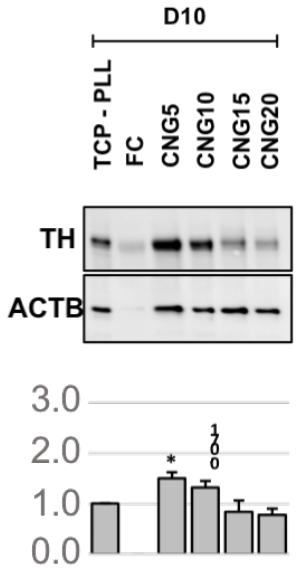

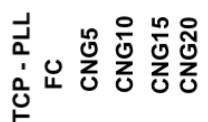

B
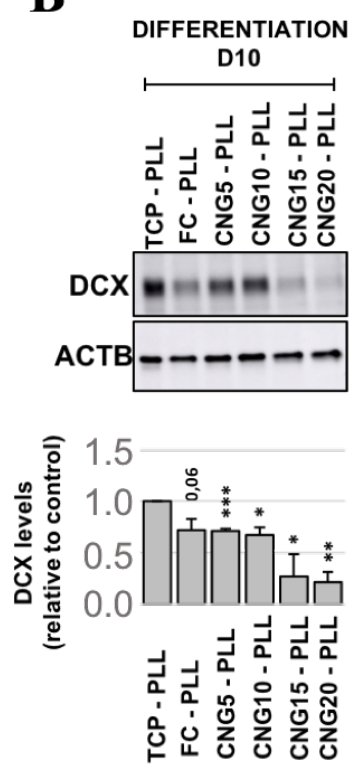

DIFFERENTIATION D10
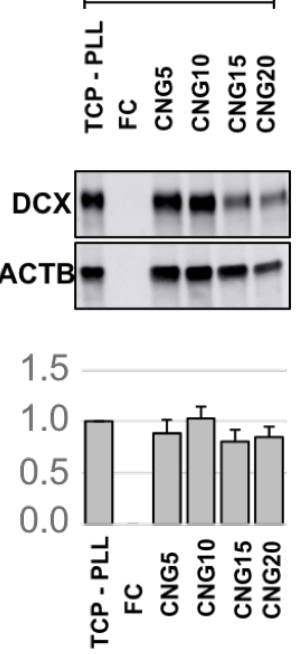

Figure S4. Representative results for western blot (WB) analysis of: A) DAn (TH), and B) immature neuron (DCX) markers, with PLL coating (left columns) and without coating (right columns), as a result of 10-days of hNSC differentiation on FC and CNG surfaces with TCP as a surface control ( $\mathrm{n}=3$ biological replicates). The ACTB gene was used as loading control.
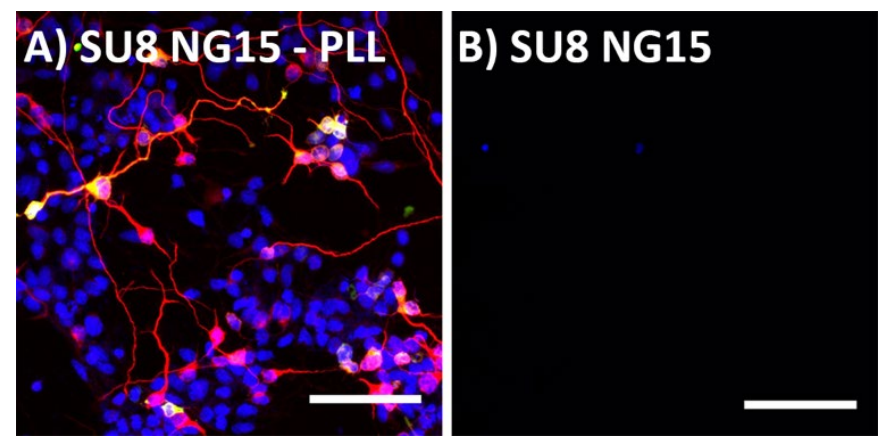

Figure S5. Characterization of hNSCs on SU8 nanograss after 10 days of differentiation followed by immunostaining (TUBB3, TH, and DAPI) and fluorescent imaging for neurogenesis and DAn generation is shown in A) PLL coated SU8 nanograss with 15 mins etch time (SU8 NG15-PLL), and B) uncoated SU8 nanograss with 15 mins etch time structures (SU8 NG15). Results show that hNSCs do not adhere to SU8 nanograss structures in the absence of PLL (Figure B), while in case of a PLL coating, the hNSCs can adhere, grow and differentiate into neurons (Figure A). Due to the potential toxic nature of SU8 material, they cannot generate similar amounts of DAn as on the CNGs and flat substrates. Scale bars $100 \mu \mathrm{m}$. 
Table S6. Statistical significance analyses among PLL coated CNG for DAn: $\mathrm{TH}^{+}$Neurons / Dapi.

\begin{tabular}{lccccc}
\hline \multicolumn{1}{c}{ Topographies } & Mean Diff & $95 \%$ Cl of Diff & Significant? & Summary & P-Value \\
\hline CNG5 vs. CNG10 & -4.583 & -6.244 to -2.923 & Yes & $* * * *$ & $<0.0001$ \\
\hline CNG5 vs. CNG15 & -8.417 & -10.08 to -6.756 & Yes & $* * *$ & $<0.0001$ \\
\hline CNG5 vs. CNG20 & -6.5 & -8.16 to -4.84 & Yes & **** & $<0.0001$ \\
\hline CNG10 vs. CNG15 & -3.833 & -5.494 to -2.173 & Yes & $*$ & 0.0002 \\
\hline CNG10 vs. CNG20 & -1.917 & -3.577 to -0.2564 & Yes & $*$ & 0.0267 \\
\hline CNG15 vs. CNG20 & 1.917 & 0.2564 to 3.577 & Yes & 0.0267 \\
\hline
\end{tabular}

Table S7. Statistical significance analyses among uncoated CNG for DAn: $\mathrm{TH}^{+}$Neurons / Dapi.

\begin{tabular}{lccccc}
\hline \multicolumn{1}{c}{ Topographies } & Mean Diff & $95 \%$ Cl of Diff & Significant? & Summary & P-Value \\
\hline CNG5 vs. CNG10 & -3.167 & -4.325 to -2.008 & Yes & ${ }^{* * * *}$ & $<0.0001$ \\
\hline CNG5 vs. CNG15 & -8.083 & -9.242 to -6.925 & Yes & ${ }^{* * * *}$ & $<0.0001$ \\
\hline CNG5 vs. CNG20 & -6.333 & -7.492 to -5.175 & Yes & $* * * *$ & $<0.0001$ \\
\hline CNG10 vs. CNG15 & -4.917 & -6.075 to -3.758 & Yes & $* * *$ & $<0.0001$ \\
\hline CNG10 vs. CNG20 & -3.167 & -4.325 to -2.008 & Yes & $* * * *$ & $<0.0001$ \\
\hline CNG15 vs. CNG20 & 1.75 & 0.5917 to 2.908 & Yes & $* *$ & 0.0059 \\
\hline
\end{tabular}

Table S8. Statistical significance analyses among PLL coated CNG for neurons: TUBB3.

\begin{tabular}{|c|c|c|c|c|c|}
\hline Topographies & Mean Diff & $95 \% \mathrm{Cl}$ of Diff & Significant? & Summary & P-Value \\
\hline CNG5 vs. CNG10 & -6.75 & -9.759 to -3.741 & Yes & $* * *$ & 0.0003 \\
\hline CNG5 vs. CNG15 & -11.33 & -14.34 to -8.324 & Yes & $* * * *$ & $<0.0001$ \\
\hline CNG5 vs. CNG20 & -9.5 & -12.51 to -6.491 & Yes & $* * * *$ & $<0.0001$ \\
\hline CNG10 vs. CNG15 & -4.583 & -7.592 to -1.574 & Yes & ** & 0.0056 \\
\hline CNG10 vs. CNG20 & -2.75 & -5.759 to 0.259 & No & ns & 0.0702 \\
\hline CNG15 vs. CNG20 & 1.833 & -1.176 to 4.842 & No & ns & 0.2123 \\
\hline
\end{tabular}

Table S9. Statistical significance analyses among uncoated CNG for neurons: TUBB3.

\begin{tabular}{lccccc}
\hline \multicolumn{1}{c}{ Topographies } & Mean Diff & $95 \%$ Cl of Diff & Significant? & Summary & P-Value \\
\hline CNG5 vs. CNG10 & -1.75 & -4.265 to 0.765 & No & ns & 0.1578 \\
\hline CNG5 vs. CNG15 & -7.167 & -9.682 to -4.652 & Yes & **** & $<0.0001$ \\
\hline CNG5 vs. CNG20 & -7.083 & -9.598 to -4.568 & Yes & **** & $<0.0001$ \\
\hline CNG10 vs. CNG15 & -5.417 & -7.932 to -2.902 & Yes & *** & 0.0004 \\
\hline CNG10 vs. CNG20 & -5.333 & -7.848 to -2.818 & Yes & ns & 0.0005 \\
\hline CNG15 vs. CNG20 & 0.08333 & -2.432 to 2.598 & No & & 0.9443 \\
\hline
\end{tabular}

